\title{
LA REGLA DE LA 'PREVALENCIA DE LAS CONDICIONES PARTICULARES SOBRE LAS CONDICIONES GENERALES'. SU PROYECCIÓN EN EL ÁMBITO DE LA INTERPRETACIÓN DE LOS CONTRATOS, Y EN ESPECIAL EN EL CONTRATO DE SEGURO*
}

\section{THE RULE OF 'PREVALENCE OF SPECIFIC CONDITIONS OVER GENERAL CONDITIONS,' ITS PLACE IN THE CONTEXT OF CONTRACTUAL INTERPRETATION AND ESPECIALLY THE INSURANCE POLICY}

\author{
Carlos Ignacio Jaramillo J. ** \\ Fecha de recepción: 27 de noviembre de 2016 \\ Fecha de Aceptación: 6 de diciembre de 2016 \\ Disponible en línea: 30 de diciembre de 2016
}

\section{Para Citar este articulo/To cite this article}

\begin{abstract}
Jaramillo Jaramillo, Carlos Ignacio, La Regla de la 'prevalencia de las condiciones particulares sobre las condiciones generales'. Su proyección en el ámbito de la interpretación de los contratos, y en especial en el contrato de seguro, 45 Rev.Ibero-Latinoam.Seguros, 59-103 (2016). http://dx.doi.org/10.11144/Javeriana.ris45.rpcp

doi:10.11144/Javeriana.ris44.rpcp
\end{abstract}

* Artículo de investigación que se integra al grupo de Investigación en Derecho Privado de la Facultad de Ciencias Jurídicas de la Pontificia Universidad Javeriana.

A la memoria imperecedera del ilustre Profesor, Andrés OrdóÑEz OrdóÑEz, (q.e.p.d.), brillante, riguroso, metódico y consagrado académico patrio, a quien me unió una acerada relación personal y académica de más de tres décadas, sin duda uno de los más aventajados y eruditos cultores del Derecho de Seguros a lo largo de su historia en Colombia y en Latinoamérica, del que siempre aprendí y seguiré aprendiendo con fruición, en testimonio de mi arraigada estimación, inmaculado respeto, incombustible gratitud, e inconmensurable admiración intelectual.

** Profesor Titular y Ex Decano Académico de la Facultad de Ciencias Jurídicas de la Pontificia Universidad Javeriana. Doctor por la Universidad de Salamanca (Ph. D. y Doctor Europeus), Ex Magistrado de la Corte Suprema de Justicia (Sala de Casación Civil), Conjuez de la Corte Suprema de Justicia, Miembro Correspondiente de la Academia Colombiana de Jurisprudencia, Árbitro nacional e internacional y Miembro de la Corte de Arbitraje de la Cámara de Comercio de Bogotá, Colegiado de Número del Colegio de Abogados Comercialistas, Miembro del grupo de investigación en Derecho Privado y del Centro de Estudios de Derecho Privado de la Facultad de Ciencias Jurídicas de la Universidad Javeriana, Miembro fundador y miembro de honor de la Asociación Iberoamericana de Derecho Privado; Miembro del Instituto Latinoamericano de Derecho Privado; Miembro de la Red Ius Civile Salmanticense (Academia Salmantina de Civilistas Latinoamericanos); Miembro del Centro di Studi Guiridici sui Diritti dei Consumatori de la Universidad de Perugia, Socio Honorario de la Società italiana degli Studiosi del Diritto Civile, SISDiC, Presidente Honorario de la Asociación Colombiana de Derecho de Seguros, ACOLDESE, y Ex Presidente Mundial de la Asociación Internacional de Derecho de Seguros, AIDA. 


\section{RESUMEN}

En el ámbito del Derecho de contratos, por excelencia, uno de los temas de mayor resonancia y también vigencia, es el atinente a la interpretación contractual, no sólo en lo que atañe a los llamados contratos de libre discusión o paritarios, sino también, y de modo sobresaliente, frente a los denominados contratos de contendido predispuesto, contratos por adhesión a condiciones generales, y contratos de consumo, entre otras manifestaciones de la contratación contemporánea. Por consiguiente, examinar las modernas reglas de interpretación de los contratos en el Derecho comparado y en el colombiano, resulta de la mayor utilidad, en concreto la arraigada 'regla de la prevalencia de las condiciones particulares sobre las condiciones generales', núcleo de la contratación en la actualidad, tanto desde una perspectiva general, como desde una perspectiva individual, en especial en la esfera reservada al contrato de seguro, en el que la pauta en comento, ciertamente, reviste singular importancia, hasta el punto de que buen aparte de su estructuración y desarrollo ulterior, en efecto, ha tenido lugar en sede de la dinámica y enriquecida relación aseguraticia.

Palabras claves: Interpretación del contrato; Interpretación del seguro; Póliza de seguro; Condiciones generales; Condiciones particulares; Prevalencia de las condiciones particulares; Reglas de interpretación; Hermenéutica Contractual. 


\begin{abstract}
In the context of Contracts Law, one of the most resounding topics, but also one of the most current ones, as to contractual construction, not only with respect to non-standardized contracts but also standard-form contracts and consumption contracts, among other expressions of current business transactions, examining the modern rules of interpretation of contracts in the light of comparative law and Colombian law is useful, in particular, the rather well accepted rule of "prevalence of specific conditions over general conditions," which is a sort of nucleus of contracting practices today, both from a general perspective and an individual perspective, especially as to what is related to the insurance agreement (insurance policy) where such rule is of the utmost importance, to the extent that a great deal of its structure and subsequent development, in fact, has materialized as to the active and rich insurance legal relationship.
\end{abstract}

Key words: Contractual interpretation; insurance interpretation; insurance policy; general conditions; specific conditions; prevalence of specific conditions; interpretation rule; contractual hermeneutics.

\title{
SUMARIO
}

1.Prolegómenos 2. Somera ubicación de la regla de la prevalencia de las condiciones particulares. 3. Enunciación y naturaleza de las reglas y criterios de interpretación de las condiciones generales 4 . Regla de la prevalencia de las condiciones particulares sobre las generales 4.1. Enunciado básico, fuente de la regla y cometido de la misma 4.2.Tipología, configuración y breve caracterización.4.3. Fundamento, significado y alcances 4.4. Reconocimiento normativo. Legislación comparada, principialística internacional y jurisprudencia colombiana. 4.5. Presupuestos básicos. 4.6. Limitaciones. El carácter beneficioso de las condiciones generales y su determinación. 5. Otros supuestos: contradicción entre condiciones generales, únicamente. 


\section{PROLEGÓMENOS}

Uno de los temas de mayor valía en el Derecho contemporáneo, en general, y en el Derecho de contratos, en particular, estriba en la interpretación, por traducirse en uno de los actos humanos más sublimes y grandilocuentes (acto interpretativo), al mismo tiempo que de elevada y rigurosa responsabilidad, lo que aconseja realizarlo no sólo con observancia de los más exigentes cánones y presupuestos en la esfera hermenéutica, sino también con suma cautela y con el más esmerado y prudencial cuidado (ex abundante cautela), de suerte que no es laborío cualquiera -o rutinario-, uno más del amplio o dilatado quehacer jurídico.

De allí que en esta ocasión, convencidos de la trascendencia que reviste la interpretación de los contratos, tema que ha despertado en nosotros manifiesto interés en el pasado, no sólo en el campo general del contrato, sino también en la órbita del contrato de seguro, en especial, deseamos detenernos en uno de los aspectos de mayor relieve en la actualidad, concretamente el atinente a la apellidada regla de prevalencia de las condiciones particulares sobre las generales, indiscutidamente una de las más empleadas en la praxis negocial, con mayor preponderancia en la órbita aseguraticia, conforme se anticipó.

Al fin y al cabo, el contrato de seguro es uno de los más escrutados en sede judicial, hasta el punto de que un apreciable número de elucubraciones y doctrinas que forman parte de la hermenéutica contractual moderna son producto del examen individual de la referida relación aseguraticia en sus diferentes dimensiones y tipologías.

Por ello, desde la perspectiva en comento, el seguro es fértil en grado sumo, a la par que receptáculo de una serie de instituciones, figuras y postulados de sinigual significado y penetración, v.gr: la buena fe (contrato de uberrima bona fides), con todo lo que ello implica en el campo de los apellidados deberes secundarios de conducta; la confianza legítima y racional inculcada en las partes, sobre todo en cabeza del tomadorasegurado; la aleatoriedad de la relación jurídico-aseguraticia; el carácter predispuesto y adhesivo -o de adhesión- que, de ordinario, reviste dicho contrato; la intensidad y proyección de los deberes de información y autoinformación; la dependencia genético-funcional del reaseguro respecto al seguro (conexidad y redes contractuales), y un largo etcétera. 
En este orden de ideas, es diáfano que el contrato de seguro, como pocos, es terreno abonado para el análisis de la temática propuesta, pues como anticipábamos, y ahora lo refrendamos, en el territorio hermenéutico un apreciable número de reflexiones actuales se han llevado a cabo gracias a la auscultación del seguro, un negocio jurídico pletórico en 'juridicidad' -y en 'cientificidad'-, dueño de las más variadas, amén de novísimas aplicaciones jurídicas.

De hecho, mutatis mutandis, el seguro es una especie de laboratorio en el cual se destilan, prueban y refinan numerosas teorías, y también se elaboran fiables respuestas y remedios en sede del Derecho de contratos, como se esbozó, y en el ámbito de la responsabilidad civil -o Derecho de daños-, igualmente fecundo, merced a la íntima relación existente entre el seguro y la referida responsabilidad civil ${ }^{1}$.

No es de extrañar entonces que la regla objeto de análisis en esta oportunidad, vale decir la de la prevalencia de las condiciones -o estipulaciones-particulares sobre las generales, en gran medida, deba su desarrollo y maduración al Derecho de seguros, en particular a los señeros aportes de legisladores, jueces y doctrinantes. Lo propio acontece en punto a las demás reglas hermenéuticas y, en general, a la interpretación de los contratos, tributaria de aquél.

Expresado de otro modo, y sin ambages, el estudio del contrato de seguro ha sido, en sus distintas manifestaciones y ramificaciones, manantial en el que, a menudo, bebe la ley, la jurisprudencia y la doctrina para efectos de hidratar y enriquecer la encomiable tarea de quienes por oficio interpretan los contratos. Así lo comprueba la práctica forense y el creciente número de decisiones judiciales que, con estribo en una relación aseguraticia, resuelven las controversias suscitadas entre las partes contratantes, las que no sólo sirven de apoyatura al caso particular escrutado, sino también a otros más, incluidos aquellos que no descansan en una de tales relaciones, por vía de ejemplo en un arrendamiento financiero, en una agencia mercantil, en un contrato de distribución, en un contrato de cuenta corriente, en una relación de consumo no aseguraticia y, en fin, en la amplia gama de contratos atípicos e innominados.

1 Cfr. Carlos Ignacio JaRAmillo J. La configuración del siniestro en el seguro de la responsabilidad civil, Universidad Javeriana y Editorial Temis, Bogotá, 2011, p.p. 25 y s.s. 
Así las cosas, al amparo de lo expresado en precedencia, y de la mano de algunos trabajos previos ${ }^{2}$, nos anima la idea de pasarle revista a la regla de prevalencia de las condiciones particulares sobre las generales, para lo cual tendremos muy presente los insumos emergentes de la teoría general de la interpretación en la hora de ahora, así como los de la interpretación aplicada al contrato de seguro, la que ha sido de indiscutida utilidad, más de lo que prima facie pareciera, motivo por el cual este modesto escrito, además, persigue una justiciera reivindicación del papel desempeñado por él (contrato de seguro), en lo pertinente.

\section{SOMERA UBICACIÓN DE LA REGLA DE LA PREVALENCIA DE LAS CONDICIONES PARTICULARES}

La regla -o pauta- de la prevalencia, en estrictez, pese a que posee una serie de vasos comunicantes con otras reglas hermenéuticas ordinarias o tradicionales (centenarias), suele ser ubicada en un vértice diverso, esto es el que se identifica con las nuevas manifestaciones del contrato en la contemporaneidad, por oposición a la visión más convencional caracterizada por la presencia de contratos de libre discusión (paritarios, de negociación, gré a gré, entre otras denominaciones).

Ello explica que, en términos muy latos, acudiendo a una clasificación de origen didáctico recreada por nosotros en diferentes oportunidades, tal regla la inscribamos en las apellidadas 'reglas modernas' de interpretación de los contratos, por oposición a las que hemos llamado 'tradicionales', esto es a esas pautas decantadas a través de centurias -y hasta milenios-, justamente por ser vertebrales e informadoras de la quintaesencia hermenéutica, constituyéndose en la 'caja de herramientas' básica de todo intérprete, no por convencionales ayunas de relevancia.

Efectivamente, el hecho de emplear la expresión reglas 'modernas' $\mathrm{u}$ otra similar que denote el mismo cometido, no persigue encumbrar unas y relativizar -o minusvalorar-otras, en concreto las tradicionales, a pretexto de que lo moderno, per se, es más trascedente, a la par que actual. Muy por el contrario, las apellidadas reglas tradicionales, clásicas

2 Vid. Carlos Ignacio JaRAmillo. Principios rectores y reglas de interpretación de los contratos, Universidad Javeriana, Universidad de Perugia y Grupo Editorial Ibañez, Bogotá, 2016, p.p. 537 y s.s. 
o convencionales, son esenciales y, de suyo, fundantes, hasta el punto que las 'modernas', en puridad, no son plenamente autosuficientes, puesto que, ad baculum, conforme a la dinámica asignada a cada una de ellas, se apoyan en la teoría general de la hermenéutica, es decir en la doctrina capital - o céntrica- que emerge de los cánones que preexisten de antaño y que se traducen, en tal virtud, en faro para todo hermeneuta, así el negocio jurídico llamado a ser escrutado sea uno de los más sofisticados, actuales y modernos, v.gr: un contrato de leasing, de joint venture, de vending, de franquicia, etc., o uno de los contratos de consumo, según sea el caso.

Al fin de cuentas, la arquitectura de cada uno de ellos es contractual, con todo lo que eso envuelve, por manera que, ab initio, en línea de principio rector, están sujetos a ser interpretados con arreglo a las directrices convencionales de todos los contratos, por 'lozanos' que sean -o parezcan-, obviamente en consonancia y en armonía con las reglas modernas de índole hermenéutica, las que no son compartimentos estancos sino parte de un conjunto de postulados (red hermenéutica) que, al unísono, persiguen un simétrico propósito: revelar el contenido fidedigno del acuerdo o negocio jurídico celebrado por los extremos de la relación negocial.

Por eso, sin distingo, reglas tradicionales y modernas, así entendidas, integran un mismo tejido, en cuyo caso el acto hermenéutico, concebido como un prototípico 'proceso', está conformado por un haz de pautas que, in casu, deben ser atendidas y, por ende, aplicadas por el hermeneuta, in concreto, en atención a su conocido carácter vinculante.

En este orden de cosas, teniendo en cuenta la irrupción de la consabida fenomenología de la contratación masiva, predispuesta, serial y estandarizada, inexistente en el Derecho histórico (civil law y common law), al igual que en el movimiento codificador decimonónico (códigos pioneros o de primera generación del siglo XIX), así como su indiscutida incidencia en el esquema convencional del contrato de libre discusión (o paritario) de origen más liberal, nos asiste la idea de analizar las reglas y los criterios más emblemáticos de los cambios registrados en el cosmos contractual a lo largo de la centuria anterior y de la que corre, muy especialmente en sede de la contratación contemporánea, signada por la presencia de contratos de -o por-adhesión, contratos celebrados con arreglo a condiciones generales y contratos de consumo, estereotipada 
por una visible asimetría de poderes entre el predisponente, de un lado, y el adherente o consumidor, del otro, en lo pertinente, tal y como ya lo manifestamos.

Dicho de otro modo, a tono con el nuevo paradigma contractual reinante, en sí mismo diverso al imperante en otros estadios del Derecho occidental, según lo historiamos con antelación, es conveniente hoy igualmente ocuparse de las tildadas reglas modernas de interpretación de los contratos, con el objeto de atender la realidad circundante, la que exige un complemento a la dogmática general preexistente (prius), a modo de complemento necesario (plus), so pena de desconocer la evolución registrada en más de un siglo, de suyo de la mayor incidencia y valía, en particular de la anunciada regla de la prevalencia de las condiciones particulares de cara a las generales.

Del mismo modo, importa aclarar de antemano que las mencionadas reglas modernas -incluida la señalada regla de la prevalencia-, en ocasiones, están íntimamente vinculadas o relacionadas con algunas reglas tradicionales, aunque dicha sintonía no supone identidad plena, en la medida en que, sin perjuicio del parentesco, tienen perfiles propios, inherentes a las mutaciones y cambios en la contratación actual. Es lo que sucede, entre otros ejemplos más, con la regla contra proferentem y la pro consumatore - o favor consumatoris-, esta última más amplia y bienhechora, como se observará.

Ahora bien, en lo que concierne con la delimitación temática, es necesario efectuar algunas precisiones, en aras de demarcar mejor el alcance de nuestro escrito, el que obviamente es limitado a concretos aspectos de la interpretación de los contratos, pues como lo hemos expresado en más de una ocasión, nos anima no el deseo de completitud y el de la exhaustividad, sino el de la concreción de cara a específicos temas, ad exemplum el relativo a las apellidadas reglas modernas de interpretación, muy especialmente de cara a los contratos predispuestos y a los contratos por adhesión a condiciones generales, aun cuando importa advertir que, desde una perspectiva normativa el referido principio pro consumatore legislativamente está conectado en el plano hermenéutico con las condiciones generales, sin referir, por lo menos en forma expresa, a los contratos por adhesión, u a otro esquema similar de índole negocial, 
como sí se hace, en cambio, en el artículo 37, intitulado: “Condiciones negociales generales y de los contratos de adhesión".

De hecho, el varias veces mencionado artículo 34 del nuevo Estatuto del Consumidor, rotulado: "Interpretación favorable", expresamente conecta el acto interpretativo con las aludidas condiciones, y lo hace en los siguientes términos que memoramos: "Las condiciones generales de los contratos serán interpretadas de la manera más favorable al consumidor....", lo que no excluye, per se, la presencia de los consabidos contratos por adhesión, en tanto en cuanto estén integrados por condiciones generales, sin importar para ello, desde el ángulo en comento, si también contienen condiciones particulares, según se referirá más adelante.

Por eso nosotros preferimos aludir a 'contratos por adhesión a condiciones generales', a fin de cobijar el acto adhesivo y las condiciones generales, las que en todo caso no pueden tener vida propia por fuera de un contrato o acuerdo de voluntades. De ahí que se apelliden condiciones generales de contratos, de contratación, de la contratación y, en fin, de otras maneras, todas ellas atañederas a un contrato. Incluso el art. 34 en cita, liga o asocia 'condiciones generales' y 'contrato': "Las condiciones generales de los contratos".

\section{ENUNCIACIÓN Y NATURALEZA DE LAS REGLAS Y CRITERIOS DE INTERPRETACIÓN DE LAS CONDICIONES GENERALES}

Aun cuando no existe un catálogo taxativo de las reglas -o principios- $-\mathrm{y}$ de los criterios de interpretación de las condiciones generales de contratación en el moderno Derecho de los contratos, si hay acuerdo en que las pautas tradicionales, sin restarles relevancia, deben ser complementadas con otras que, a tono con la realidad de la contratación predispuesta y masificada, consulte mejor esta nueva dimensión, cónsona con el renovado paradigma $\mathrm{u}$ orden contractual reinante, al que ya hemos hecho referencia, así no tengan como cometido subvertir el sistema hermenéutico tradicional, inspirado en la contratación individual -paritaria o de libre discusión-.

Dichas pautas, empero, no cuentan-todas- ni con la unanimidad de la jurisprudencia, ni de la doctrina, ni tampoco con el exequatur legislativo, 
aun cuando las más socorridas, en línea de principio, son las siguientes: la regla de prevalencia de las condiciones particulares sobre las condiciones generales; la regla de la condición más importante; la regla de la condición más beneficiosa; las reglas contra proferentem y pro consumatore; la regla de interpretación restrictiva; la regla de la conexidad negocial, reglas de la interpretación de los contratos atípicos y la regla de la interpretación más razonable.

También hay que reconocer que tampoco es pacífico el punto relativo a la naturaleza de las reglas en mención, dado que, para un sector autoral es válido dudar de que sean arquetípicas y genuinas reglas, así contribuyan, de alguna manera, a la tarea del intérprete, pero por otra vía. Es lo que sucede, fundamentalmente, tratándose de la apellidada regla de prevalencia de las condiciones generales sobre las particulares, por estimarse que, en el fondo, encuadra mejor en otros esquemas, v.gr. en el de los 'requisitos negativos de inclusión' de las condiciones generales, o como 'regla de desincorporación' de las mismas, o como 'regla de graduación o establecimiento de rango's.

Por nuestra parte, respetando otras opiniones, preferimos revestirlas de la naturaleza de 'reglas hermenéuticas', precisamente por el rol que cumplen en el establecimiento del contenido y del significado contractuales, como se apreciará, a la par que por la dinámica a ellas asignada, la que varía en función de las diversas circunstancias, incluida la referida pauta de la prevalencia, signada por la convergencia de un apreciable número de variables, muchas de ellas confirmatorias de su carácter de regla, cabalmente entendida (esclarecimiento del contenido volitivo), a lo que cabe adicionar razones metodológicas que justifican su rótulo y su desarrollo 'in complexu', conforme lo hace no sólo la communis

3 Vid. Josep FERRER RiBA, quien no obstante cuestionarse válidamente en torno a la naturaleza en mención, cabalmente expresa que en este caso se "...establece una graduación puramente funcional que tiene su operatividad en el plano hermenéutico”. De allí que, “...por su naturaleza interpretativa debe ser ponderado conjuntamente con el resto de reglas de hermenéutica contractual y cuya observancia -tal y como ha venido entendiendo la jurisprudencia, respecto de los distintos cánones de interpretación contractual puede ser denunciada en casación". "Reglas de interpretación", en Comentarios a la ley de condiciones generales, Civitas, Madrid, 2002, p. 362.

De igual modo, en guarda de reafirmar la naturaleza hermenéutica de esta regla de prevalencia, importan dos hechos adicionales: en primer lugar, la consideración de subjetiva y no de canon objetivo de interpretación, y la calificación de regla, pauta, canon o directriz de tipo hermenéutico que, de antiguo, le reconoce la jurisprudencia internacional. Cfr. Manuel GARCíA Amigo. Condiciones generales de los contratos, Editorial Revista de Derecho Privado, Madrid, 1969. p. 200. 
opinio, sino hasta la propia ley, según tiene lugar en España, entre otros ejemplos más, en la medida en que la Ley sobre Condiciones Generales de Contratación (LCGC), bajo el elocuente y textual epígrafe de "reglas de interpretación", en su artículo 6, numeral primero, se ocupa de la precitada regla de prevalencia, encaminada a conjurar la "...contradicción entre las condiciones generales y condiciones particulares..."4.

Al fin de cuentas, encarar responsablemente la fenomenología de la contradicción -o inarmonía-, y darle una solución jurídica al problema que sea menester resolver en torno a los derechos y obligaciones de las partes contratantes, envuelve una labor hermenéutica, bien entendida, pues como lo recuerda el profesor español Angel CARRASCO, en función del mencionado artículo 6, numeral primero de la citada Ley de Condiciones Generales -que es el que en España gobierna la regla de la prevalencia en cuestión-, “. . .la contradicción o la oscuridad constituyen el resultado....de la interpretación"s, puesto que, de ordinario, no se asoma al rompe, o a simple vista, con sólo efectuar una desprevenida lectura ('golpe de ojo'). Generalmente se requiere algo más (plus), dado que es muy probable que sea necesario efectuar una visión de conjunto (cosmovisión contractual), ingresando entonces en predios de la interpretación.

De hecho, como es posible que, a términos del referido -y peculiarnumeral primero, sea necesario hacer un juicio de valor para elucidar si en un momento determinado es más beneficioso para el adherente el contenido de una condición general versus la particular (cláusula 'más beneficiosa'), dicho juicio será hermenéutico, por antonomasia ${ }^{6}$.

Por eso, a priori, no es recomendable restarle toda incidencia hermenéutica a la descrita tarea, sin duda valiosa. Ya hemos expresado en otro momento que el intérprete, en especial el juez, no puede ser asimilado a un 'lector óptico', únicamente; su rol es muy otro, ciertamente, y no

4 Art. 6. "Reglas de interpretación. 1. Cuando exista contradicción entre las condiciones generales y las condiciones particulares específicamente previstas para ese contrato, prevalecerán éstas sobre aquellas, salvo que las condiciones generales resulten más beneficiosas para el adherente que las condiciones particulares".

5 Angel Carrasco Perera . Derecho de contratos, Aranzadi-Thomson Reuters, Pamplona, 2010, p. 69.

6 Según lo reconoce enfáticamente el estudioso profesor español Juan Roca Guillamón, "La determinación de cuál sea la cláusula más beneficiosa es, pues, una pura tarea de interpretación". "Reglas de interpretación de las condiciones generales de los contratos", en Condiciones generales de la contratación y cláusulas abusivas, Lex Nova y Consejo General de los Colegios Oficiales de Corredores de Comercio, Valladolid, 2000, p. 326. 
se compadece con la asignación de funciones meramente mecánicas, carentes de valoración y de ponderación.

En sentido similar, en general, el profesor peruano Carlos Sото Coaguila, no duda en opinar, con ocasión de esta interesante polémica, que "En la doctrina se discute si de la prevalencia es una regla de interpretación o una regla de inclusión. Al respecto, es mayoritario el sector doctrinario que la reconoce como una regla de interpretación y ello se refleja no sólo en la legislación comparada, sino también en la propia doctrina" 7 .

Finalmente, en el campo del contrato de seguro, pletórico por excelencia en materia hermenéutica (cátedra viva), según lo hemos reiterado en más de una ocasión, la communis opinio incluye en la temática que nos ocupa a la regla de la prevalencia de las condiciones particulares frente a las generales, por entenderla como una fiable, a la par que útil pauta, en concreto como una de las "...reglas especiales" de "interpretación de la póliza y del contrato", conforme lo expresa el recordado y erudito profesor argentino, Issac HALPERIN ${ }^{8}$, al igual que lo pregona la profesora

7 Carlos Sото Coaguila. "Las reglas de interpretación de los contratos en el derecho peruano", en Tratado de la interpretación del contrato en América Latina, Grijley, 2007, p. 1181.

En análogo sentido, más recientemente, el profesor Rubén STIGLITZ indiscutidamente la asigna a dicha regla el carácter de "...directiva de interpretación contractual" "Nuevos temas incorporados en la teoría general del contrato en el Código Civil y Comercial de la Nación", en Contratos en el nuevo Código Civil y Comercial, Thomson Reuters, La Ley, Buenos Aires, 2015, p. 5). Y también el Dr. Darío A. SAndoval Shaik, cuando asevera que "En la doctrina existe discusión con respecto a la naturaleza de la regla de la prevalencia; es decir si es una regla de interpretación o, por el contrario es una regla de inclusión. La mayor parte, sin embargo, se decanta por estudiarla como una regla interpretativa y esta situación se refleja en la legislación comparada". Las condiciones generales del contrato de seguro y su control interno e internacional, Universidad Complutense de Madrid, 2014, p. 243.

8 Issac Halperin. Seguros. Exposición crítica de las Leyes 17.418 y 20.091, en coautoría con el Profesor Juan Carlos Félix Morandi, Buenos Aires, 1983, p. 350. En la misma línea, la profesora Yvone LAMBERT FAIVRE, al considerar que esta regla de la prevalencia de las condiciones particulares es una regla propia y, por ende empleada en la "interpretación del contrato de seguro". Droit des assurances, Dalloz, Paris, 2005, p. 201, y el recordado y admirado profesor patrio, Dr. Andrés OrdóÑEZ OrdóÑEZ (q.e.p.d.), quien con la claridad que siempre lo caracterizó, también estimó que una de las "reglas especiales sobre interpretación del contrato" (o "específicas", como a su vez las consideró), justamente es la regla de la prevalencia. "Las nuevas tendencias del derecho de seguros en las legislaciones más recientes de los países latinoamericanos", en Revista Ibero-latinoamericana de seguros, No 40, Universidad Javeriana, AIDA-CILA, Bogotá, 2014, p.49.

Cfr. José Luis Pérez-Serrabona G, La póliza y la documentación del contrato de seguro, Editorial Comares, Granada, 2003, p.p. 112 y 113, y Walter VILLA ZAPATA. "Reglas de interpretación del contrato de seguro", en Derecho de seguros, Homenaje de la Asociación Argentina de Derecho de Seguros -Rama de la A.I.D.A- al profesor Juan Carlos Félix Morandi, Hammurabi, Buenos Aires, 2001, p.168, destacado jurista peruano muy cercano a la AIDA de tiempo atrás, reciente y desventuradamente fallecido (q.e.p.d.), quien no vaciló en considerarla como "regla de interpretación lógica". 
francesa, Marie-Hélene MALEviLle, en su importante monografía alusiva a la interpretación de los contratos de seguro terrestre ${ }^{9}$, y el docto Profesor español, Abel VeIGA Copo, para quien la "regla de la prevalencia", en idéntica dirección, es una de las "reglas interpretativas" del contrato de seguro de mayor usanza ${ }^{10}$, entre otros destacados académicos que sostienen análoga tesitura, a fortiori cuando un apreciable número de controversias, en la praxis, tiene como manantial puntuales divergencias entre lo excluido en las condiciones generales, de una parte, y lo amparado -cubierto o incluido- en desarrollo de condiciones particulares, de la otra.

Incluso hay doctrinantes que, realzando la valía de la pauta en mención, la elevan al rango de 'principio' interpretativo aplicable directamente a la relación aseguraticia. Es el caso del insigne Profesor belga, Marcel FonTAINE, quien aludiendo y describiendo los "principios de interpretación" del contrato de seguro, manifiesta que un "...principio (no escrito en el Código Civil) encuentra su aplicación, según el cual una cláusula particular prevalece sobre una cláusula general ${ }^{11}$.

En la órbita legislativa, algunas legislaciones alusivas al contrato de seguro, expresamente consagran la regla sub examine y la inscriben en el marco de la interpretación, tal y como tiene lugar en naciones como Cuba y Perú.

9 Marie-Hélene Maleville. L'interprétation des contrats d'assurance terrestre, L.G.D.J, Paris, 1996, p. 34, quien no duda en aseverar, con razón, que "La contradicción afecta los contratos de seguros y por eso es una causa de interpretación", motivo por el cual, desde esta perspectiva, entiende que "La interpretación es un verdadero azote para las pólizas mal redactadas, lacónicas o ambiguas" (op.cit, p. 4).

10 Abel Veiga Copo. "La interpretación de las condiciones en el contrato de seguro", en Revista de responsabilidad civil y seguro, p. 66. Sin embargo, en honor a la realidad, así sea cierto que el Profesor VEIGA abiertamente incluye en primer lugar como regla de interpretación del seguro a la citada regla de la prevalencia, y de que en tal virtud estime que "Dos disposiciones son contradictorias cuando una de ellas niega lo afirmado en la otra, por lo que la contradicción o discrepancia que afecta a un contrato de seguro es una causa de interpretación", tampoco es menos cierto que de la mano de la Profesora ibérica DíAZ AlABART, finalmente consideró respecto de ella que, “...en puridad no estamos ante una genuina regla de interpretación de los contratos pues su fin no es averiguar el sentido de los mismos o de las cláusulas que lo integran y en definitiva le dan vida. Realmente la regla de prevalencia es una regla imperativa sobre la cláusula que habrá de entenderse incorporada al contrato entre varias en contradicción, normalmente generales y particulares....", segunda opinión que, por respetable que sea, como en efecto lo es, no podemos compartir, por las razones esgrimidas en líneas anteriores, a las que entonces nos remitimos.

El hecho de que la regla se enuncie como imperativa, para nada desdibuja su status de pauta hermenéutica, stricto sensu. Tanto es así, por lo demás, que de ordinario las reglas de interpretación se enuncian imperativamente, según tiene lugar, por vía de ejemplo, a lo largo de los artículos 1618 a 1624 del Código Civil patrio, en lo pertinente. Vid, in extenso, nuestro trabajo: Principios rectores $y$ reglas de interpretación de los contratos, op. cit, p.p. 235 y s.s.

11 Marcel Fontaine. Droit des assurances, Larcier, Bruxelles, 1996, p. 213. 
Así, el Artículo 59 del DL 263/2008, dispone que, “La interpretación del contrato de seguro se atendrá a las siguientes reglas: 1 . el significado literal u ordinario de las palabras utilizadas, salvo las definidas expresamente en este Decreto - Ley o en su Reglamento; 2. las condiciones particulares prevalecerán sobre las generales y las especiales sobre aquellas....".

Y el Artículo IV de la Ley peruana del contrato de seguro de 2012, a su turno prescribe que, "En la interpretación del contrato de seguro se aplican las reglas siguientes:... Sexta. Las condiciones especiales prevalecen sobre las condiciones particulares y estas prevalecen sobre las generales. Las cláusulas manuscritas o mecanografiadas predominan sobre las impresas".

Del mismo modo, en sede de proyectos normativos, el célebre y difundido Proyecto de ley Modelo del contrato de seguro para Latinoamérica del insigne Profesor argentino, Juan Carlos Félix Morandi, a la altura de su art. 26, letra i, establece que, “....Las cláusulas particulares y las especiales prevalecen sobre las condiciones generales específicas y las condiciones generales. Las condiciones generales específicas sobre las condiciones generales, y, las cláusulas manuscritas o mecanografiadas predominan sobre las impresas"" 12 .

Y ya para concluir con este aparte, según se constató, es muy común en materia de seguros, sobre todo en el siglo anterior por la tecnología reinante, referir a la prevalencia de condiciones manuscritas frente a condiciones mecanografiadas, justamente por entender que las primeras son expresión de una voluntad más decantada y reveladora, en sí misma llamada a primar, lo que explica que ellas se consideren particulares, $\mathrm{y}$ no condiciones generales ${ }^{13}$. Lo propio, en su caso, tratándose del primado

12 En materia de proyectos de ley, el Proyecto presentado a la Dirección General de Seguros en el año 1954 por parte de los visionarios Don Ignacio de Larramendi y Don Ernesto Caballero Sánchez, en su artículo 63, a su turno estatuía que "Para la interpretación de las pólizas, además de tenerse presente el principio de la buena fe en que se basa el contrato de seguro, se estará en lo posible a las siguientes normas: ....3) Las cláusulas manuscritas tiene preferencia sobre las impresas y las particulares sobre las generales".

13 Bien anotó el mencionado Profesor I. HalPERIN que, "Las cláusulas manuscritas predominan sobre las impresas, porque son las particulares o especiales del contrato". Seguros, Exposición crítica de las leyes 17.418 y 20.091, op. cit, p. 357, opinión compartida por los autores franceses André FAVREE Rochex y Guy Courtieu, quienes han expresado que, "Las cláusulas manuscritas o dactilografiadas priman, en caso de oposición, a las cláusulas impresas". Le droit du contrat d'assurance terrestre, L.G.D.J, Paris, 1998, p. 57. 
de las condiciones mecanografiadas de cara a las condiciones objeto de impresión, de tal suerte que aquellas se estimarían como particulares (status), por revelar una atendible intención de alterar el alcance y contenido de las que, ex ante, han sido masivamente impresas (condiciones generales).

\section{REGLA DE LA PREVALENCIA DE LAS CONDICIONES PARTICULARES SOBRE LAS GENERALES}

\subsection{Enunciado básico, fuente de la regla y cometido de la misma}

En términos muy simples, grosso modo, esta regla se enuncia en función del diáfano efecto que persigue (concepción teleológica), expresando la prevalencia de las condiciones particulares sobre las condiciones generales de contratación, las cuales, como se ha bosquejado en precedencia, son producto de los nuevos fenómenos que caracterizan la contratación contemporánea, sobre todo los atinentes a la masificación, a la estandarización y a la globalización de los contratos, a lo que se agrega su tecnificación, automatización y despersonalización, según las circunstancias ${ }^{14}$.

Por consiguiente, teniendo en cuenta la irrupción de las señaladas condiciones en el cosmos contractual y el cambio experimentado en punto tocante con la forma o manera de celebrar los contratos en las últimas décadas (nuevo paradigma u orden contractual), se ha hecho necesario introducir una serie de reglas o pautas hermenéuticas enderezadas a dotar al intérprete de mejores elementos de juicio para poder fijar el alcance y el significado de lo pretendido por los contratantes, en el presente caso a conjurar la discrepancia ontológica entre lo plasmado con carácter más global -y anticipado- en las denominadas condiciones, estipulaciones o cláusulas generales, y las apellidadas, por oposición, condiciones, estipu-

14 Dicha fenomenología obviamente cobija la relación aseguraticia -aun cuando no a la reaseguraticia, por regla-, como quiera que el seguro ha sido uno de los prototipos de contrato masificado (contrato masa) y también estandarizado (contrato estándar), como lo confirman millones de seguros celebrados a lo largo de la pasada centuria y lo corrido de la presente, concretamente por la presencia sostenida y sistemática de las supraindicadas 'condiciones generales'. De ahí que el reputado Profesor, Don Joaquín GARRIGUES, expresará que, "Son las condiciones generales, al propio tiempo, un resultado y una exigencia de la contratación en masa. Tienden de una vez y para siempre a facilitar la conclusión masiva de contratos. Contrato de seguro terrestre, Imprenta Aguirre, Madrid, 1980, p. 8. 
laciones o cláusulas particulares, dueñas de una específica y diferenciada misión negocial, como se mencionará seguidamente.

De allí que ella se personifique como una regla de prevalencia, de prelación, de primacía y también, consecuentemente, de resolución de discrepancias en el plano hermenéutico, pues unas y otras, a la vez, no podrían reinar in toto, lo que justifica que se haya arbitrado un instrumento para el efecto, el que exigirá más que una mera labor mecánica, según se examinará, corroborándose su raigambre hermenéutica y su naturaleza subjetiva, como se anticipó, sobre todo en atención a la presencia de las aludidas condiciones particulares, llamadas, ex definitione, a particularizar e individualizar el negocio jurídico celebrado -y si se permiten las expresiones a 'aterrizarlo', a 'residenciarlo' y a 'domesticarlo'-.

En relación con la fuente de la indicada regla, si bien es cierto en algunas naciones expresamente existe con carácter global o general (leyes especiales, o códigos civiles), y en otros con un carácter más normativo individual (legislación predicable del contrato de seguro, entre otras ejemplos), tampoco es menos cierto que no se condiciona su eficacia únicamente a una exigencia o autorización normativas, como lo tiene establecido la jurisprudencia y la doctrina que, al unísono, de tiempo atrás acuden a esta pauta de la prevalencia de las condiciones particulares, la que puede justificarse, de modo panorámico, si se quiere con asiento en el centenario postulado de la fuerza vinculante del contrato (pacta sunt servanda), entre nosotros reconocido por el artículo 1602 del Código Civil, y refrendado por la Constitución Política, y por otros textos ex lege, así como por la misma lógica y razonabilidad, según lo confirma un sector autoral ${ }^{15}$.

Finalmente, en lo tocante con su cometido, cumple registrar que en la esfera teleológica la regla de la prevalencia, en su auténtica esencia, persigue evitar que la contradicción, que la incoherencia o inarmonía referidas al contenido contractual, se enseñoreen $y$, por ende se paseen

15 María Laura Estigarriba Biber. "Evolución de los principios de interpretación de los contratos, con especial referencia a la República Argentina”, en Tratado de la interpretación del contrato en América Latina, T.I, Grijley, Lima, 2007, p. 314, quien anota que la 'regla de la prevalencia' "importa que el intérprete, en caso de contradicción entre una condición general y una cláusula particular, debe estar a lo que disponga esta última. El fundamento deriva de la misma lógica", lógica que en el campo hermenéutico, es la constante, hace continua presencia. No en vano, la interpretación, como lo hemos expresado en otras ocasiones, es un procedimiento lógico (logicidad hermenéutica). 
por la relación negocial, dejando a su paso perplejidad, confusión, oscuridad, sorpresa y desolación, en contravía de la claridad, precisión y coherencia requeridas en materia prestacional y en cumplimiento de la grandilocuente misión asignada al contrato, pilar insustituible de la sociedad y del Derecho, no sólo en la actualidad, sino ab antique, y en el futuro, como es de esperar.

Al fin de cuentas, las secuelas dimanantes de la contradicción -o choque interno entre dos o más contenidos- no son de poca monta, dado que eclipsan el sentido y contenido unívocos que las cláusulas de un contrato debe tener, circunstancia que explica, de una parte, el deseo creciente del legislador por eliminar la contradicción, la inarmonía y la incoherencia, y de la otra, en caso de que ellas afloren, de arbitrar idóneos mecanismos encaminados a superarlas ${ }^{16}$, y de ese modo garantizar una conclusión más armónica, amén de razonable y justa.

\subsection{Tipologia, configuración y breve caracterización}

En consonancia con lo inmediatamente manifestado, es de memorar que en la contratación masificada y seriada, a menudo, convergen dos tipos de estipulaciones disímiles (summa divisio) que, a diferencia de lo acontecido con los contratos de libre discusión o negociación, paritarios o individuales, concurren en la contratación moderna y que integran el tejido negocial (regulación contractual o lex privatum), el que, in casu, podrá llegar a ser materia de interpretación-calificación y eventualmente integración-: las condiciones generales y las particulares, sin perjuicio de la entronización de un tertium genus por algún sector de la doctrina: las condiciones especiales, parecer que no ha contado con el favor de la communis opinio, ni del legislador comparado -en forma amplia o generalizada-, por estimar, con razón, que no es necesario o forzoso ampliar el ámbito del indicado binomio, de por sí suficiente -o pleno-, rectamente entendido, aun cuando hay que reconocer que en materia aseguraticia, es cierto, se alude y se acude más a dicha categorización (condiciones especiales) ${ }^{17}$.

16 Vid. Carlos Ignacio Jaramillo J. La doctrina de los actos propios. Valor y significado de la regla latina venire contra factum proprium en el ámbito contractual, op. cit., p. 134 y ss.

17 "La distinción de las condiciones en generales y particulares da cuenta de todas las reglas de un contrato que tienen origen en la voluntad privada, sin dejar espacio para un tertium genus. Por ello las denominadas 'condiciones especiales' y demás cláusulas contenidas en documentos que en ocasiones acompañan al cuerpo principal de un contrato (condiciones adicionales, anexos, etc.), deben ser reconducidas a una de 


\section{Por ello el entramado contractual en la actualidad, es la usanza, hunde sus raíces en ambos tipos de estipulaciones que, por su configuración,}

las categorías citadas: serán condiciones generales o particulares....Llegar a discernir unas y otras puede resultar muy difícil”. Josep FerRer Riba. Reglas de interpretación, op. cit., p. 370.

Sin embargo, como anotábamos, en el ámbito aseguraticio es más común que en otros encontrar puntuales referencias a las precitadas condiciones o cláusulas 'especiales', referencia que, como se registró, hacen incluso legislaciones como la cubana y peruana concernientes al contrato de seguro, aunque hay que reconocer que la tendencia legislativa internacional es otra: darla pábulo únicamente al binomio integrado por las condiciones generales y por las particulares, lo que a nuestro modesto juicio es correcto, dado que esta aproximación binaria la estimamos suficiente, a la par que precisa, evitándose innecesarias ramificaciones o derivaciones, no siempre claras, además, pues se prestan para evidentes equívocos y dubitaciones.

De hecho, la simple denominación de 'especiales', en un momento determinado, denota que ellas se aproximan o acercan más a las particulares que a las condiciones generales. Especial, lo recuerda el Diccionario de la Lengua Española, es "Singular o particular, que se diferencia de lo común o general" (se destaca), confirmándose que, en rigor, no resulta indefectible auspiciar una tercera categoría -o aún una subdivisión o subclasificación-, en razón de que las dos convencionales o tradicionales, ya referidas, son autosuficientes y, por esa vía plenas, sobre todo las particulares que, semánticamente, desde la perspectiva en cuestión, se acompasan mejor con las llamadas 'especiales', en concreto con la misión que algunos suelen atribuirles.

No obstante, en la praxis aseguradora cuando se hace mención a las mencionadas 'condiciones especiales', frecuentemente ello tiene lugar para darle cabida a una aplicación concreta de las condiciones generales, más que a las particulares, aun cuando al respecto no campea la unanimidad, lo anticipamos, pues algunos -los más- las adscriben a las generales y otros a las condiciones particulares, así sea en forma más implícita o indirecta. Por eso es por lo que el sapiente Maestro J. Efrén Ossa G., a tono con la primera vertiente, puntualiza que "La póliza de seguros ofrece ordinariamente dos clases de condiciones: a) las condiciones particulares y b) las condiciones generales. Subclase de estas es la de las condiciones especiales que suelen incorporarse en determinados tipos de póliza en armonía con su función específica o con la naturaleza de los bienes asegurados". Teoría general del seguro. El contrato, Temis, Bogotá, 1991, p. 253.

En análoga dirección, Don Julio Castello Matrán y Don Antonio Guardiola, en su acreditado Diccionario de seguros, anotan que, “...junto a las condiciones generales y particulares, se encuentran las condiciones especiales, cuya misión más frecuente es matizar o perfilar el contenido de algunas recogidas en aquellas. En esta línea, el establecimiento de franquicias a cargo del asegurado, la supresión de algunas exclusiones y la inclusión de otras nuevas, son condiciones de este tipo frecuentes en las pólizas". Diccionario Maprfre de seguros, Fundación Mapfre, Madrid, 2008, p. 347.

A su vez, el distinguido profesor chileno Osvaldo Contreras Strauch, en consonancia con la segunda vertiente, ha expresado que, "En toda póliza de seguros se distinguen dos partes principales, denominadas 'condiciones particulares' y 'condiciones generales'. En algunos casos se hace referencia a 'condiciones especiales' y a la 'carátula de la póliza', pero estas últimas denominaciones no son otra cosa que partes de las condiciones particulares, o formas que ellas revisten en algunos casos". Derecho de seguros, Legal Publising y Thomson Reuters, Santiago, 2014, p. 176.

Y el autor español Fernando DEL CAÑo EsCUDERO, pareciendo confirmar la existencia de ambas tesituras, señala que "Las condiciones especiales...suelen estar mecanografiadas y tienen por objeto modificar o aclarar las condiciones generales, o regular situaciones no previstas en éstas. Algunos también incluyen en este grupo de condiciones, aquellas que siendo propiamente generales, se refieren a cada una de las modalidades que cubre una póliza y no son comunes a todas las modalidades". "El contenido mínimo de la póliza en la Ley de Contrato de Seguro", en Comentarios a la Ley de Contrato de Seguro, T. I, Colegio Universitario de Estudios Financieros, Madrid, 1982, p. 371, doctrinante que igualmente recrea un fallo del Tribunal Supremo español, el que en sentencia del 24 de febrero de 1944, entendemos que funcionalmente identifica condiciones especiales y particulares, al concluir que “...entre las cláusulas generales y las especiales, hay que atender a éstas, porque las cláusulas especiales tienen precisamente por objeto alterar o aclarar lo convenido en las condiciones comunes, sobreponiendo a éstas un sentido más concluyente y más concretamente al caso singular de que se trate". 
significado y alcances, conviene no confundir (generales, y particulares, stricto sensu). Muy por el contrario, resulta imperativo diferenciar, así sea sucintamente, en consideración a su sustantividad y entidad, de suerte que, como lo expresara nuestra Corte Suprema de Justicia, en tratándose de la contratación masiva, o la "...ajustada mediante la adhesión a estipulaciones predispuestas", suele presentarse una "...coexistencia de dos tipos de clausulado, uno necesariamente individualizado; que suele recoger los elementos esenciales de la relación; y el otro, el reglamentado en forma de condiciones generales, caracterizado por ser general y abstracto...." 18 .

En efecto, las llamadas condiciones generales, como emerge de su propio rótulo, son aquellas que, ab origine, tienen una vocación de mayor espectro -y cobertura- que las particulares, habida consideración que persiguen irradiar una serie o pluralidad de relaciones futuras (tráfico de masa), confirmando de este modo su generalidad -y no su individualidad o especificidad-, nota prototípica suya y, por ende, definitoria, en cuyo caso, in concreto, “....constituyen, consideradas en su conjunto, la trama esencial del contrato", según gráficamente le expresa el profesor F. Messineo ${ }^{19}$.

Por eso mismo, el autor español José Antonio BALLESTERos Garrido, no vacila en afirmar que "Son condiciones generales de la contratación las que hayan 'sido redactadas con la finalidad de ser incorporadas a una pluralidad de contratos'. Este requisito hace referencia a que las condiciones generales tienen como objeto regular de manera uniforme los contratos que celebre el predisponente, como una manifestación del tráfico en masa, que le permite una racionalización y reducción de costes..., pero también...una regulación única para todos ellos..."20.

Son pues generales las condiciones que, en la esfera finalística, a posteriori, uniforman el contenido básico negocial y que han sido redactadas unilateralmente por el predisponente -o por otro sujeto diverso- y no por el adherente, quien no participa en dicha construcción, de tal suerte que, por completo, permanece relegado en lo que a la factura de las mismas

18 Corte Suprema de Justicia, Sentencia del 4 de noviembre de 2009.

19 Francesco Messineo. Doctrina general del contrato, T.I, E.J.E.A, Buenos Aires, 1952, p. 443.

20 José Antonio Ballesteros Garrido. Las condiciones generales de los contratos y el principio de la autonomía de la voluntad, Bosch, Barcelona, 1999, p. 74. 
concierne, tanto que, desde esta perspectiva, cuando adhiere a ellas, in futurum, adhiere a una obra ajena ('operación adhesiva'), además que lo hace en bloque, puesto que "...no pueden ser discutidas libre y previamente" (art. 2, letra f), Ley 1328/2009), vale decir, con resignación, porque en tales condiciones "...no puede modificarlas, ni puede hacer otra cosa que aceptarlas...." (numeral 4, art. 5, Ley 1480/2011), lo que se acompaña del consabido acto de su imposición ${ }^{21}$.

Como lo establece el artículo 1 de la Ley sobre condiciones generales de contratación española de 1998, "Son condiciones generales de la contratación las cláusulas predispuestas cuya incorporación al contrato sea impuesta por una de las partes, con independencia de la autoría material de las mismas, su apariencia externa, de su extensión y de cualesquiera otras circunstancias, habiendo sido redactadas con la finalidad de ser incorporadas a una pluralidad de contratos".

Así las cosas, el margen y tipo de contribución del adherente - $\mathrm{O}$ cocontratante del predisponente- suele ser ninguno, de tal forma que en la praxis es un típico convidado de piedra, ya que el acto de predisposición, tratándose de este tipo de condiciones, es unilateral ${ }^{22}$. Por ello, como bien lo realza el profesor de la Universidad de Roma, Massimo BIANCA, "Las condiciones generales se caracterizan no sólo por cuanto se destinan a regular la generalidad de las relaciones establecidas por una parte, sino también porque son predispuestas unilateralmente por ella", al mismo tiempo que impuestas, dado que la imposición igualmente resulta necesaria, en la medida en que “...no sólo la predisposición, sino además el requisito de la imposición” ${ }^{23}$.

Las condiciones particulares, a su turno, pese a integrar igualmente el contenido contractual específico - cuando son efectivamente estructura-

21 La Corte Suprema de Justicia, en sentencia del 2 de febrero de 2001, entendió que son condiciones generales de contratación, “...aquellas disposicionesde naturaleza volitiva y por tanto negocial a las que se adhiere el tomador sin la posibilidad real o efectiva de controvertirlas, en la medida en que han sido prediseñadas unilateralmente...sin dejar espaciopor regla generalpara su negociación individual" (M.P. Carlos Ignacio Jaramillo J., Sala de Casación Civil).

22 Cfr. Giorgio De Nova. "Le condizioni generali di contratto", en Trattato di diritto privato. Obbligazioni e contratti, UTET, Torino, 1982, pp. 104 y 105. Vid. Santiago Alvarez González. Condiciones generales en la contratación internacional, La Ley, Madrid, 1992, p. 27.

23 José Javier González de Alaiza Cardona, y Francisco Pertínez Vílchez. "Los contratos de adhesión y la contratación electrónica”, en Tratado de contratos, T. II, Tirant lo blanch, Valencia, 2011, p. 1594. Vid. Adolfo DI MAJo. "Il contenuto del contratto", en La disciplina generale dei contratti, Giapichelli Editore, Torino, 1999, p. 607. 
das y prohijadas-, se cimientan en una etiología y teleología enteramente diversa, lo que afianza la idea de su sustantividad y talante propios.

Es así como su cometido panorámico, en su estado de máxima pureza, estriba en flexibilizar la rigidez y conjurar la abstracción de las condiciones generales, atendidas su plasticidad e individualidad, en la inteligencia de que se incardinan, in concreto, en una relación particular real y específica, es decir de 'carne y de hueso', en la que queda impresa la huella genética distintiva de cara a otros condicionados abstractos e impersonales, a la par que generales. Por eso se suele manifestar que ellas revelan cabalmente la genuina intención interpartes y, por esa vía, una voluntad decantada y reflexionada, en línea de principio, sin perjuicio de que, excepcionalmente, como lo registraremos en folios posteriores, se puedan estructurar 'condiciones particulares predispuestas', pero con vocación individualizadota (concretatio) ${ }^{24}$.

En dicha orientación, el Dr. Darío A. Sandoval Shaik, entiende que “...será condición particular, la que se inserte dentro de un contrato en forma específica para ese tipo de contrato, frente a la condición general que es incluida en un contrato de manera indiscriminada en el sentido de que también puede aplicarse a una pluralidad de futuros contratos, adquiriendo sentido en todos ellos, mientras que la condición particular sólo cobra sentido en ese tipo de contrato. Esta regla se basa en la idea de que las condiciones particulares expresan mejor que las condiciones generales la voluntad común de las partes contratantes"25.

Y los propósitos específicos de las condiciones particulares, a su turno, fincan básicamente en precisar o complementar, en modificar, en alterar, o en dejar sin efectos alguna -o algunas- de las previsiones inmersas en las condiciones generales, sin que exista en todo caso un numerus clausus de hipótesis respecto a su uso y a sus finalidades ${ }^{26}$, así

24 En sentencia del 18 de enero de 1909, quedó claro que para el Tribunal Supremo español, condición particular, entendida “....como singular y particularmente concertada para cada contrato determinado, es la que real y verdaderamente revela la deliberada y manifiesta intención de las partes". De allí que el profesor Manuel García Amigo, ratificando la prevalencia en cita, concluyó a finales de la década de los sesenta que "...las condiciones especiales, prevalecen sobre las condiciones generales, como reveladoras de la voluntad de las partes". Las condiciones generales de los contratos, Op. cit, p. 200

Darío A. Sandoval Shaik. Las condiciones generales del contrato de seguro y su control interno e internacional, op. cit., p. 242.

26 Por nuestra parte, a este mismo respecto, ya habíamos tenido ocasión de confirmar en la esfera aseguraticia, que “...por ser elaboradas entre el asegurador y el tomador, y por contener una expresión 
sea cierto que, por lo común, según lo registran con tino los profesores STIglitz, habitualmente "... las condiciones particulares tienen como propósito consignar los elementos específicos de la relación singular, y en ese caso se suman a las condiciones generales. En otras, apuntan a las sustitución de una estipulación general negocial, y, como en el caso, traducen una expresión de voluntad que atiende al mecanismo tradicional en la formación del contrato, prevalecen sobre la condición general"27.

En esta última dirección, el primer inciso del artículo 986 del moderno Código Civil y Comercial argentino de 2014, preceptúa lo siguiente: "Cláusulas particulares. Las cláusulas particulares son aquellas que, negociadas individualmente, amplían, limitan, suprimen o interpretan una cláusula general”.

Algo similar, aun cuando no con la misma precisión y pertinencia, puede derivarse de lo estatuido por la parte final del artículo 42 de la Ley 1480 de 2011 (Estatuto del consumidor), pues pese a la redundancia en que incurre, en lo pertinente, revela la idea de particularidad negocial, con todo lo que ello implica, al pregonar que en lo que dice relación con las cláusulas abusivas, a fin de “...establecer la naturaleza y magnitud del desequilibrio, serán relevantes todas las condiciones particulares de la transacción particular que se analiza" (se destaca).

más decantada de la voluntad, se deben aplicar preferentemente en relación con las generales, máxime cuando, por ser posteriores, traducen una intención contraria y adversa, que para el efecto, deberá ser tomada en cuenta...". Carlos Ignacio Jaramillo J. Estructura de la forma en el contrato de seguro, Temis, Bogotá, 1986, p. 167. Cfr. Abel VeIga Copo. Caracteres y elementos del contrato de seguro. Póliza y clausulado. Universidad Sergio Arboleda. Biblioteca Jurídica Diké. Bogotá. 2010. pp. 433 y ss., quien concluye en la misma dirección que existe una diáfana y general “... supremacía de una cláusula particular sobre una condición general en caso de discrepancia entre ambas”.

El citado Tribunal Supremo español, en Sentencia del 24 de febrero de 1944, lo reiteramos, puso de relieve que las condiciones especiales se diferencian de las generales, pues “...tienen precisamente por objeto alterar o aclarar lo convenido en las condiciones comunes sobreponiendo a éstas un sentido más concluyente adaptado al caso singular que se trate". Años más tarde, el mismo Tribunal, en Sentencia del 18 de enero de 1989, refrendó que "Las condiciones particulares, en cuanto singular y particularmente concertadas para un contrato determinado, son las que real y verdaderamente revelan la deliberada y manifiesta intención de las partes contratantes, derogando o anulando lo consignado en las condiciones generales".

27 Rubén y Gabriel Stiglitz. Contratos por adhesión, Depalma, Buenos Aires, 2015, p. 75. Sobre este mismo punto, el primero de los citados e ilustres profesores, expresó en otra ocasión que, “...las condiciones particulares deben considerarse como una deliberada modificación o cancelación (según el caso) de la condición general. Y el fundamento está dado en que la primera refleja, de ordinario, el acuerdo que fue objeto de negociación...la regla de autonomía particularmente concertada, revela la auténtica y real intención de las partes de derogar, en el caso singular, la condición general redactada por el profesional uniformemente para sus futuros contratos". Rubén Stiglitz. Contratos civiles y comerciales, T. I, Abeledo-Perrot, Buenos Aires, 1998, p. 456. 
A su turno, corroborando la capacidad individualizadora inherente a las condiciones particulares y su consecuente potencialidad de revelar lo realmente querido por las partes en un asunto contractual determinado, nuestra Corte Suprema de Justicia, en sentencia del 24 de julio de 2012, puso de presente que "...Para averiguar el querer de los obligados, a más del tenor literal de sus cláusulas y las directrices establecidas en los artículos 1618 a 1624 del Código Civil, 5 y 823 del Código de Comercio, debe tener en cuenta el intérprete diversos factores que inciden en el acuerdo, tales como las condiciones particulares de los intervinientes y su proceder en los diferentes momentos contractuales, esto es, antes, durante y después de su celebración, de tal manera que se refleje de manera precisa el ánimo que los inspiró a vincularse...."28.

En este orden de cosas, se entiende entonces que las condiciones particulares, por lo ya señalado, están llamadas a primar en línea de principio rector, por encarnar la real intentio de ambas partes contratantes que, de lo general, descendieron válida y negocialmente a lo más particular, de suerte que como lo enseña con agudeza el profesor chileno Jorge LóPEZ SANTA MARÍA, “...la situación concreta tiene que quedar mejor reglamentada por una cláusula discutida que por una cláusula abstracta, forjada a priori, en el aire"29.

Lo mismo concluye el profesor argentino Fernando J. LóPEZ DE ZAVALÍA, al puntualizar, con claridad, que en relación con las particulares es 'obvio' que prevalecen sobre las generales; "así lo impone la naturaleza de unas y otras, puesto que las primeras provienen de un proyecto, de un esquema abstracto, mientras que las segundas son la manifestación concreta, adaptada al caso, de tal manera que si unas y otras son expresión de la voluntad, las particulares los son incondicionalmente, mientras que las generales en cuanto no sean derogadas por aquellas"30.

28 Corte Suprema de Justicia, Sentencia del 24 de julio de 2012.

29 Jorge López Santa María. Los contratos, Parte general, Editorial Jurídica de Chile, 1986, p. 115. Cfr. Claudia Lima MARQues, profesora brasilera que considera que las "cláusulas pactadas individualmente derivan su fuerza del hecho de que son el fruto de la voluntad de ambas voluntades y no solamente expresión de la voluntad del que formuló unilateralmente las condiciones generales de contratación". "Notas sobre a intererpretaçao dos contratos no directo privado brasileiro: As linhas gerais sobre interpretação do Código Civil de 2002 e do Código de Defensa do consumidor de 1990", en Tratado de la interpretación del contrato en América Latina, T.I, Grijley, Lima, 2007, p. 651.

30 Fernando J. López de Zavalía. Teoría de los contratos. Parte general., Víctor P. de Zavalía, Buenos Aires, 1984, p. 78. Análogamente, las autoras españolas Silvia DíAz Alabart y María Teresa Alvarez Moreno, corroboran que en esta materia, "Es lógico que se dé mayor relevancia a las condiciones 
En plena armonía con lo expresado, en concreto con las razones que, en principio, justifican la prevalencia de las condiciones particulares, el reciente Anteproyecto de Código Mercantil español de 2014, estatuye en su artículo 430-4, que "Las condiciones particulares prevalecen sobre las condiciones generales".

Dos comentarios finales es aconsejable efectuar en torno a la delimitación de las mencionadas condiciones particulares.

En primer lugar, ello es importante, que su nomen, en desarrollo de arraigados postulados de índole jurídico-contractual, no emana invariable y expresamente de lo señalado por las partes, o de lo acordado por la vía adhesiva, según el caso. Una condición será particular, en el más estricto rigor, cuando consulte, en principio, con la teleología mencionada, es decir cuando persiga exceptuar -modificar, ampliar, atenuar, alterar, etc.- el contenido de una condición general (plasticidad negocial).

Por lo tanto su acertada calificación de tal, conforme acontece con la calificación del contrato, no depende de lo que las partes o una de ellas considere o estime ${ }^{31}$, pues como lo confirma el profesor español Francisco Pertiñez Vilchez, "En la determinación de que cláusulas de un contrato deben tenerse por condiciones particulares, no debe atribuírsele ninguna trascendencia a las manifestaciones que al respecto haga el predisponente.

particulares puesto que en la mayor parte de los casos son reflejo de la voluntad común de las partes, y aún si también han sido predispuestas, lo lógico es que se acomoden mejor a las específicas circunstancias del contrato en el que se incluyen". Manual de derecho del consumo, Reus, Madrid, 2016, p. 90.

31 Contractus magis ex partis quam verbis discernuntur. Vid. Carlos Ignacio JARAmillo J. Interpretación, calificación e integración del contrato, Universidad Javeriana y Grupo Editorial Ibañez, Bogotá, 2014, p. 161 y ss., monografía en la que afirmamos de esta importante operación que "La calificación del contrato, aún más particular y específica que las actuaciones anteriores [interpretación e integración], en cambio, tiene como confesado propósito el establecimiento de su naturaleza jurídica, de su rostro o morfología (quaestio iuris), lo que supondrá el esclarecimiento previo de su arquitectura, en lo medular, lo que se hará a través de la valoración primigenia de los hechos y, claro está, es lo primordial, del contenido contractual previamente definido (interpretación) y de la auscultación de las normas jurídicas que, de una otra manera, disciplinan el tipo contractual respectivo, ese que precisamente, in casu, está sometido al escrutinio del intérprete, sin perjuicio de la constatación contraria, es decir de que no está inmerso en una determinada regulación, evento en el cual así también lo señalará, por tratarse de un arquetípico juicio iuris, se insiste en ello".

"Es entonces la calificación una operación de innegable relevancia jurídica, pues de ella dependerá la floración de una serie de consecuencias determinadas en función de la conclusión tipológica a la que finalmente se arribe, bien sea validando lo establecido al respecto por las partes (ex voluntate), o modificándolo en el evento de que no se haya procedido a cabalidad en ejercicio de la autonomía privada...". 
Las condiciones no son particulares porque unilateralmente así lo decida el predisponente, sino de acuerdo con su naturaleza" 32 , lo que sirve de estribo, además, para dudar de una genuina y tercera categoría de condiciones: las 'especiales', según ya lo mencionamos anteriormente, y aún de que las mismas sean una subdivisión de una de las dos tradicionales: generales y particulares.

Y en segundo lugar, así no sea de permanente ocurrencia o usanza, hay que observar que, excepcionalmente, a tono con lo expresado en precedencia, una condición particular puede no ser el origen exclusivo de la factura y estructuración de ambas partes contratantes, como generalmente ocurre, en opinión de un sector doctrinal. Por ello, esta anotación la efectuamos más a título de excepción, y no de regla, a fin de no restarle fuerza a la misma, y de no contribuir a minar su enunciado, a lo que se suma el hecho de que, por lo común, se le atribuye la calidad de particular a las 'condiciones negociadas'.

Quienes admiten este tipo de 'condiciones particulares', lo hacen sobre la base de admitir que una de las notas relevantes de las mismas descansa en la particularización -o individualización- que se consigue a través de las mismas, la que justamente contrasta con el carácter general de las otras (las generales), tal y como tiene lugar en el Derecho español, por vía de ejemplo, en la inteligencia de que el artículo 6, numeral primero de su Ley de Condiciones Generales de la Contratación, ya mencionado por nosotros, caracteriza a las condiciones particulares por ser "...especificamente previstas para ese contrato" (se destaca).

Así lo afirma, ad exemplum, el profesor Jesús Alfaro, quien anota que "...deben considerarse también condiciones particulares aquellas cláusulas que, aún habiendo sido obra unilateral del empresario y a las que el adherente únicamente haya prestado su aceptación, hayan sido previstas específicamente para este contrato"33.

32 Francisco Pertíñez Vílchez. "Los contratos de adhesión y la contratación electrónica", en Tratado de contratos, T. II, Tirant lo blanch, Valencia, 2011, p. 1617.

33 Jesús Alfaro Aguila-Real. Las condiciones generales de la contratación, Civitas, Madrid, 1993, p. 299. Cfr. Javier PAGADOR L., al recordar que condiciones particulares “... son tanto aquellas que hayan sido especialmente negociadas entre las partes como aquellas otras que no lo hayan sido, sino que son obra unilateral del predisponente (unilateralmente predispuestas, por tanto), a las que el adherente se limita a prestar su aceptación, pero que no han sido previstas para una pluralidad de contratos, sino, tan sólo, específicamente para el contrato respecto de la cual hallan aplicación", Condiciones generales y cláusulas contractuales predispuestas, Marcial Pons, Madrid, 1999, p. 518. 
Finalmente, una vez descrito el panorama general de esta temática, es decir desde una perspectiva global, como tal predicable en principio de todos los negocios jurídicos con cláusulas predispuestas, conviene manifestar que el contrato de seguro no es la excepción. Al fin y al cabo, según lo hemos expresado antes, por antonomasia es el tipo contractual que quizá mejor se sintoniza con dicha bipartición, en razón de que unas y otras, en efecto, son el entramado y, por ende, el basamento contractual aseguraticio, un referente en el cosmos negocial, hasta el punto de que como lo confirmaran los celebérrimos profesores galos, Maurice PICARD, y André BESSON, "Condiciones generales y condiciones particulares forman un todo" 34 ; son la carne y el hueso del seguro: su corpus, integralmente entendido, y ciertamente comprendida hasta su propia alma.

En consonancia con la anunciada realidad jurídica, según habíamos tenido ocasión de anotar otrora, "A diferencia de las generales, las condiciones particulares del contrato de seguro, como su nombre claramente lo indica, se elaboran de manera individual y específica para cada contrato. En ellas desaparece la idea serial que adjetiva a las condiciones generales del negocio, propias de la contratación en masa, y prevalece el concepto de singularidad, en contraposición al de uniformidad. Se elaboran conjuntamente entre el asegurador y el tomador, [en lo pertinente], ya que son llamadas a dotar de flexibilidad al negocio jurídico. Responden con mayor claridad al cometido de autorregular intereses, pues, a través del instrumento revelador y técnico de la autonomía privada, las partes, al hacer uso de las condiciones particulares, especifican e individualizan su relación. Con su empleo, se evidencia la posibilidad de atemperar la rigidez de...las condiciones generales de contratación".

En similar sentido, reconociendo la existencia de varios 'subgrupos' de condiciones particulares, el profesor Josep FERRER R, observa que hay “...condiciones predispuestas e impuestas por uno de los contratantes, pero que lo han sido específicamente para un contrato. Estas últimas no son fruto de un acto bilateral de autonomía privada, pero tampoco son condiciones generales, por estar faltadas de generalidad". Reglas de interpretación, op. cit., p. 371.Cfr. Silvia Díaz Alabart. Reglas de interpretación, op. cit., p. 206., y M. Coca PAYERAS. "Comentario al art. 10.1.b), LGDCU", en Comentarios a la Ley General de Defensa de los Consumidores y Usuarios, Madrid, 1992, p. 327.

34 M. Picard y A. Besson. Les assurances terrestres. Le contrat d'assurance, T, I, L.G.D.J, Paris, 1982, p. 88.

En sentido similar, Don Joaquín GarRigues ya había indicado respecto de las generales, que “... constituyen, con las condiciones particulares, la lex contractu, estableciendo en forma precisa y unitaria los derechos y obligaciones de las partes....". Contrato de seguro terrestre, op. cit, p. 8. Otro tanto, in globo, expresó el Profesor Juan Carlos Félix Morandi, al recordar que “...las condiciones o cláusulas de un seguro son las normas que disciplinan el contrato de seguro". Estudios de derecho de seguros, Ediciones Pannedille, Buenos Aires, 1971, p. 187. 
Así las cosas, a la sazón concluimos entonces que “...las condiciones particulares, por reflejar el contenido específico e individual de la relación asegurativa, están llamadas a prevalecer sobre lo dispuesto en las condiciones o cláusulas generales del contrato en caso de duda o notoria contradicción, pues por ser elaboradas de consuno entre el asegurador y el tomador, y por contender una expresión más decantada de la voluntad, se deben aplicar preferentemente en relación con las generales, máxime cuando por ser posteriores, traducen una intención contraria y adversa, que para el efecto, deberá ser tomada en cuenta"35.

Por su parte, el mencionado Profesor MoRAndi, reseñó en su oportunidad que, "Las condiciones 'particulares' son aquellas establecidas específicamente para cada contrato, como las referentes a la persona del asegurado, a la naturaleza del interés asegurable, a la suma asegurada, a la individualización del bien cubierto por el seguro, a la prima, a la duración de la relación contractual, etc., y se hallan generalmente dactilografiadas".

“Las condiciones 'generales' son, en cambio, las elaboradas preventivamente y adoptadas uniformemente para todos los contratos de la misma rama. Se refieren a la 'Ley de las partes contratantes', al riesgo cubierto, a las exclusiones de cobertura, a las cargas u obligaciones del asegurado, al cambio del titular del interés asegurable, a la caducidad por el incumplimiento de obligaciones y cargas, etc....A estas últimas se les ha considerado como fuente principal del derecho viviente del seguro...." 36

35 Carlos Ignacio JaRAmillo J. La estructura de la forma en el contrato de seguro, Temis, Bogotá, 1986, p. 158 y s.s.

Tales condiciones particulares, en línea de principio rector, persiguen en el seguro la concreción de diversos aspectos espacio-temporales, subjetivos, objetivos, cuantitativos, jurídicos (elementos esenciales del tipo contractual y delimitación del riesgo), entre otros cometidos más. Es así, in concreto, como el artículo 1047 del Código de Comercio, sin agotarlos, enunciativamente enlista una nomina significativa de ellos, así: "La póliza de seguro debe expresar además de las condiciones generales del contrato: 1) La razón o denominación social del asegurador; 2) El nombre del tomador; 3) Los nombres del asegurado y del beneficiario o la forma de identificarlos, si fueren distintos del tomador; 4) La calidad en que actúe el tomador del seguro; 5) La identificación precisa de la cosa o persona con respecto a las cuales se contrata el seguro; 6) La vigencia del contrato, con indicación de las fechas y horas de iniciación y vencimiento, o el modo de determinar unas y otras; 7) La suma aseguradora o el modo de precisarla; 8) La prima o el modo de calcularla y la forma de su pago; 9) Los riesgos que el asegurador toma su cargo: 10) La fecha en que se extiende y la firma del asegurador, y 11) Las demás condiciones particulares que acuerden los contratantes" (se destaca).

36 Juan Carlos F. Morandi. Estudios de derecho de seguros, op. cit, p. 188. 
Por consiguiente, si las condiciones particulares en el contrato de seguro igualmente revelan con mayor fidelidad la voluntas de ambos extremos de la relación negocial, no es de extrañar, conforme se anticipó, que también prevalezcan sobre las condiciones generales, más abstractas e inclusive impersonales, así como ayunas de la concreción requerida para anclar el seguro a la realidad del caso, atendidas las circunstancias de tiempo, modo y lugar respectivas ${ }^{37}$.

\section{Por ello es por lo que acierta Don Fernando SÁnchez CALERo, cuando} con su habitual claridad, manifestó en la esfera aseguraticia que, "En caso de contradicción debe entenderse que prevalecen las condiciones particulares sobre las condiciones generales, y lo mismo sucederá cuando sean incompatibles. La prevalencia de la condición particular sobre la general encuentra su fundamento en la idea de que aquélla refleja mejor la voluntad de las partes" 38 , como a su vez acertó el Profesor Ossa, al indicar que, "...no hay duda de que son las condiciones particulares las que mejor reflejan la voluntad de los contratantes. Y de ahí también que su aplicación deba prevalecer sobre la de las generales en caso de incongruencia" 39 .

37 En armonía con el mismo planteamiento, a fuer que con el citado fundamento volitivo, el profesor Abel Veiga C., con tino, revela que "La regla de la prevalencia establece, en definitiva, la supremacía de una cláusula particular sobre una condición general en caso de discrepancia entre ambas, dado que una condición particular refleja más fidedigna y nítidamente la voluntad de las partes que una condición general. En cierto sentido, con la prevalencia se busca reconstruir la voluntad común de las partes contratantes como objetivo de la interpretación, tarea esta nada sencilla y en más de una ocasión imposible de alcanzar. Ciertamente una condición particular goza a efectos de rango y de prevalencia de una mayor autonomía privada de las partes, en las que a priori al menos hay, o debería haber, discusión, regateo, negociación del que se adolece en unas condiciones generales, donde la prerredacción y la predisposición ahogan prácticamente toda posibilidad a la negociación, restando meramente una libertad de decidir si sí o si no se contrata conforme a unas condiciones inmutables". La interpretación de las condiciones en el contrato de seguro, op. cit, p. 66.

38 Fernando Sánchez Calero. Ley de contrato de seguro, Aranzadi, Pamplona, 1999, p. 182.

39 J. Efrén Ossa G. Teoría general del seguro. El contrato,op. cit, p. 253.

En esta dirección, entre otros, el profesor Marcel FonTAINE expresa que, "En caso de contradicción entre las condiciones particulares y las condiciones generales de la póliza, si la cláusula particular omite especificar que ella deroga la cláusula general, en todo caso prevalecerá en virtud de este principio". Droit des assurances, op. cit, p. 213. Igualmente, el profesor italiano Vittorio SALANDRA, en otra de sus obras, indica que las cláusulas particulares prevalecen cuando sean 'incompatibles', “...porque las condiciones particulares representan una manifestación de la voluntad específica de las partes sobre un aspecto especial, la cual implica la voluntad de derogar la norma general". Dell' Assicurazione. Libro quarto. Delle obbligazioni, Zanichelli Editore, Bologna, 1966, p. 221. Cfr. Antigono Donati. Trattato del diritto delle asicurazioni private, T.II, Giuffrè, Milano, 1954, p. 336, Marco Rosetti. Il diritto delle assicurazioni. Il contratto di assicurazione in generale, T.I, CEDAM, Padova, 2011, p. 1038; Gianguido SCALFI. I contratti di assicurazione. L'assicurazione danni, UTET, Torino, 1991, p.105; Ernesto CABAllero SÁNChEz. El consumidor de seguros: protección y defensa, Fundación Mapfre Estudios, Madrid, 1997, p.p. 106 y 107, y Rubén Stiglitz., quien bien observa que 


\subsection{Fundamento, significado y alcances}

Ahora bien, en lo tocante con el fundamento de la regla de prevalencia sub examine, aun cuando se han esgrimido diversos argumentos para su cabal fundamentación, uno ha sido el más reiterado, amén que reconocido por su robustez y por reflejar la auténtica ratio de la prevalencia en comento, la que por ello debe ser observada en su justa dimensión, a fin de no arrasar con caros postulados en los que descansa la ciencia del Derecho, desde luego la tradicional y la presente: la autonomía privada, arquitecta de las relaciones jurídicas, incluso las de índole adhesiva y de consumo, rectamente concebida y contextualizada.

Efectivamente, tal y como ha sido esbozado, las condiciones particulares propias - o estrictas-, considerado el iter de su gestación e incorporación ulterior en el entramado negocial, denotan el vívido interés de encarar la relación contractual, pero no a través de la limitada -o en veces simbólica-adhesión in globo, sino mediante un ejercicio más depurado, analítico y reflexivo, como es más propio de la consabida autonomía, es decir sin la retórica volitiva que en ocasiones se emplea para justificar el acto adhesivo puro.

Hay pues discernimiento, y con él, correlativamente, participación consciente de los extremos de la relación negocial, en cuyo caso se estima que su voluntas, de una parte, sirve de estribo para fundamentar la existencia y, de la otra, para darle significado y fijar el alcance ordinario de las condiciones que, por particulares, son obra de ambos contratantes, inicialmente ${ }^{40}$, así una termine participando más que la otra, aun cuando la discusión en este estadio, en realidad, no es cuantitativa, sino cualitativa.

Y si ello es así, como ciertamente lo es, no es equivocado asignarle a las condiciones particulares, por ser corolario de la común intención de las partes, un valor especial $\mathrm{y}$, de contera prevalente frente al asignado

todo ello es así, efectivamente, dado que las “...condiciones particulares, importan un retorno a las reglas correspondientes a los contratos discrecionales y a sus pautas de interpretación....". Derecho de seguros, T. I, Abeledo Perrot, Buenos Aires, 1998, p. 363.

En el terreno jurisprudencial, en adición a la jurisprudencia invocada a lo largo de este escrito, advierte el Profesor francés, Jérome Kullmann, que pretoriamente se tiene establecido que las “...condiciones particulares prevalecen sobre las condiciones generales, porque ellas son especialmente adaptadas a la cobertura respectiva, mientras que las segundas tienen vocación de regir el conjunto de los contratos suscritos por el asegurador....".Lamy assurances, Kluwer, Paris, 2005, p. 271.

40 Cfr. Vittorio Salandra. "I contratti di adesione", en Rivista di Diritto. Commerciale, 1928, p. 530. 
a las generales, de hechura unilateral y de espectro global. Por eso es por lo que, en principio, están llamadas a primar, a prevalecer (regla de prevalencia), a predominar y de ese modo a facilitar el camino para que el intérprete, provisto de todos los elementos de juicio, pueda fijar el contenido y establecer el significado de lo querido y pretendido por los celebrantes del contrato.

Al respecto, como bien lo corrobora el profesor PAGADOR, el fundamento cardinal de esta regla “.... se ha situado de ordinario en el principio de autonomía de la voluntad....En efecto, se ha subrayado que la razón de ser de la regla de la prevalencia estriba en que las condiciones generales no pueden suplantar o desplazar a las cláusulas contractuales especialmente negociadas entre las partes, puesto que estas últimas son, a diferencia de aquéllas, expresión genuina de la voluntad de los contratantes, ni pueden prevalecer, en principio, frente a las cláusulas predispuestas especialmente por el empresario o profesional pero con relación a un contrato concreto, puesto que es razonable considerar que éstas se adaptan mejor (o se alejan menos de) la hipotética voluntad común de los contratantes" 41 .

En igual sentido, la profesora argentina María Laura EstigarRiBIA B, observa que “....aquello que las partes han convenido específicamente para el negocio que se interpreta deberá ser tomado como expresión del ejercicio de la autonomía de la voluntad, a diferencia de las condiciones generales, que se integran por simple adhesión. Así, las primeras deben ser consideradas como derogatorias de las segundas cuando se les opongan. Resulta atinada la previsión teniendo presente que las condiciones generales se incluyen en un contrato de forma indiscriminada, con carácter general, mientras que la condición o cláusula particular sólo cobra sentido en el contrato concreto en que se inserta, es decir, que revela la verdadera y manifiesta intención de las partes respecto al negocio jurídico"42.

No obstante lo anterior, según como se expresará ulteriormente más en detalle, un sector doctrinal y otro legislativo, inexplicablemente limitan la eficacia de esta regla de prevalencia, específicamente cuando “...

41 Javier PAgAdor L. Condiciones generales y cláusulas contractuales predispuestas, op. cit., p. 516.

42 María Laura EstigarriBia B. Evolución de los principios de interpretación de los contratos, con especial referencia a la República Argentina, op. cit., p. 316. 
las condiciones generales resulten más beneficiosas para el adherente que las condiciones particulares" (parte final del art. 6.1 de la Ley de condiciones generales de la contratación española, entre varias), limitación o excepción que amerita comentario especial, por cuanto exige diversas puntualizaciones y matizaciones, con miras a no desvirtuar la regla en estudio y, de paso, horadar de plano la autonomía privada, que naturalmente demanda atención. De lo contrario, no sólo se arrasaría con este adamantino pilar de la contratación, sino que se pulverizaría el alcance y con él el efecto de la citada regla de prevalencia, la que podría tornarse en rey de burlas, en contravía de la justicia contractual, y de su economía e imprescindible equilibrio.

Baste por ahora anticipar, de una parte, que la mejor doctrina ha contribuido a explicar cabalmente la excepción en referencia (condición más beneficiosa) y, de paso, a contrarrestar una lectura restrictiva o anulatoria de la autonomía privada -racionalmente ejercida-, en concreto de la eficacia de la regla de la prevalencia de las condiciones particulares, y de la otra, que no en todos los países existe idéntica restricción, como es el caso de Colombia, sin perjuicio de la existencia del artículo 34 de la Ley 1480 (Interpretación favorable), predicable de las relaciones de consumo, con un alcance diferente, en todo caso.

\subsection{Reconocimiento normativo. Legislación comparada, principialistica internacional y jurisprudencia colombiana}

Aun cuando hemos manifestado que no resulta forzoso que la legislación expresamente se ocupe de esta regla para que devenga vinculante en el campo jurídico, en particular en sede hermenéutica, toda vez que con arreglo a preceptos constitucionales y legales bien puede deducirse su legitimidad, entidad y pertinencia, algunos países se han ocupado de darle expresa cabida en su Derecho positivo, lo que a nuestro juicio es de buen recibo, como quiera que la explicitud contribuye ciertamente a la claridad, y a la evitación de innecesarias controversias o dubitaciones. Lo mismo acontece en el ámbito de la principialística internacional, un signo confirmatorio de la importancia que ella reviste en la actualidad, así como de su indiscutido carácter interpretativo. 
Así, sólo por vía de ejemplificación, el artículo 1342 del Código Civil italiano de 1942, dispone que "En los contratos concluidos mediante la firma de formularios dispuestos para disciplinar de modo uniforme determinadas relaciones contractuales, las cláusulas agregadas al formulario prevalecen sobre las del formulario cuando fuesen incompatibles con éstas, aunque las últimas no hubiesen sido canceladas".

Por su parte, el citado artículo 6, numeral primero, de la Ley de Condiciones Generales de Contratación española, manifiesta que, "Cuando exista contradicción entre las condiciones generales y las condiciones particulares específicamente previstas para ese contrato, prevalecerán éstas sobre aquellas, salvo que las condiciones generales resulten más beneficiosas para el adherente que las condiciones particulares".

Igualmente, el artículo 1400 del Código Civil peruano de 1984, preceptúa: "Las cláusulas agregadas al formulario prevalecen sobre las de éste cuando sean incompatibles, aunque las últimas no hubiesen sido dejadas sin efecto".

Finalmente, para no extendernos en demasía, el moderno Código Civil y Comercial argentino de 2014, en su artículo 986, estatuye: "Cláusulas particulares. Las cláusulas particulares son aquellas que, negociadas individualmente, amplían, limitan, suprimen o interpretan una cláusula general. En caso de incompatibilidad entre cláusulas generales y particulares, prevalecen estas últimas".

Ahora bien, en el campo de la principialística internacional, se registran importantes esfuerzos encaminados a buscar la unidad o, en su defecto la uniformidad en el campo del Derecho de obligaciones y contratos, especialmente.

Así sucede, entre otros, con los apellidados Principios de UNIDROIT, y con los Principios de Derecho Europeo de los Contratos.

En el primer supuesto, el artículo 2.21, puntualiza que "En caso de conflicto entre una cláusula estándar y una que no lo sea, prevalecerá esta última". 
Y en el segundo caso, el artículo 5:104 (Proyecto LANDO) señala: "Preferencia a favor de los términos negociados. Los términos pactados de manera individual tienen preferencia sobre los que no lo han sido"43.

En último lugar, tal y como tuvimos ocasión de anotar, la jurisprudencia colombiana en diversas ocasiones ha tenido oportunidad de ocuparse del tema de la prevalencia, bien explícita, bien implícitamente, dado que en temáticas tan recurrentes como las del seguro, es muy frecuente que se plantee un conflicto hermenéutico entre una condición general y una particular.

Es así como en la memorada sentencia del 4 de noviembre de 2009, expresa y cabalmente señaló en torno a la regla sub examine que, " $\mathrm{La}$ regla de la 'prevalencia' confiere preponderancia a la condición particular negociada, cuando entra en contradicción con las de carácter general; desde luego que es lógico preferir el clausulado particular, por cuando hace referencia al caso concreto, amén que, en principio, aclara o altera las estipulaciones generales".

Ahora bien, en lo que dice relación con el contrato de seguro, memoramos que, en general, las legislaciones especializadas no se ocupan de disciplinar expresamente esta regla. Sin embargo, según también lo expresamos en otro aparte del presente escrito, legislaciones como la cubana y la peruana, sí lo hacen, motivo por el cual, en aras de la concisión, nos remitimos a los textos que, in extenso, ya transcribimos.

\subsection{Presupuestos básicos}

En términos generales, se tiene establecido que son dos los presupuestos genéticos nucleares de la regla en mención.

El primero, referente a la exigencia de que ambas condiciones: la general y la particular objeto de escrutinio, sean intrínsecamente eficaces.

43 La Dra. Beatriz Verdera Izquierdo, comenta que”...el art. 5:104 establece que tendrán preferencia los términos individualmente negociados sobre los contratos realizados bajo condiciones generales de la contratación o, en masa. La redacción del Principio Europeo se ha formulado de un modo global y muy abierto, de esta manera tiene cabida no solo los contratos celebrados bajo condiciones generales de la contratación, sino todos aquellos en que se imponga a una de las partes, ya sea la total redacción o, alguna de sus cláusulas". "La interpretación de los contratos a partir de los Principios Contractuales Europeos", en Bases de un derecho contractual europeo, Tirant lo blanch, Valencia, 2003, p. 258. 
Y el segundo, atinente a que respecto a una y otra exista una discrepancia, contradicción o inarmonía en lo que a su contenido y alcance se refiere.

Se demanda la eficacia de las condiciones -o cláusulas-, por cuanto de otro modo el intérprete no podría aplicar válidamente la regla, haciendo prevalecer las particulares, en función de su contenido específico, acorde con la intentio de los contratantes. No habría 'otra' voluntas que auscultar y, de contera, hacer primar.

Expresado de otro modo, si se pretende eliminar la virtual contradicción o inarmonía existente entre una condición ineficaz y una que si lo sea, por sustracción de materia no podría hablarse con propiedad de una discrepancia, de una diferencia en el sustrato, o de una arquetípica contradicción - o enfrentamiento de contenidos-. Por eso es que se requiere la presencia 'vital' de otro texto, contenido o escrito, pues de otro modo no podría hablarse de cotejo, de comparación, y menos de prevalencia, como se acotó, dado que se exige la existencia de un 'ser', y naturalmente no de un 'no ser'.

Al respecto, anota el profesor Josep FERRER R., que "La regla de la prevalencia presupone que las condiciones contradictorias sean válidas y eficaces. Si una de ellas no lo es (p. ej.....por no haber quedado incorporada al contrato), la contradicción queda disuelta. Sin embargo, esto no significa que entonces se aplique, de modo automático, la condición subsistente. Esta consecuencia se producirá si la condición que resulta ineficaz es la general, pero no necesariamente en el caso inverso: el pacto individual, aún ineficaz, puede denotar, en vía interpretativa, la voluntad de los contratantes de apartarse de lo dispuesto en la condición general, por lo cual sería procedente llamar al derecho dispositivo o a otros medios de integración del contrato" ${ }^{44}$.

44 Josep FerRer Riba. Reglas de interpretación, op. cit., p. 372.

Lo importante en este puntual caso, confirmando que esta regla reviste naturaleza hermenéutica, como ya lo hemos indicado, es que ante la eventualidad de que las partes razonablemente hayan querido o podido exceptuar la aplicación del contenido de una condición general, el intérprete debe auscultar lo realmente pretendido, para lo cual es aconsejable que acuda a una lectura circunstanciada, a fin de darle pábulo a las circunstancias del caso, de tanta valía en materia interpretativa, a fortiori si se pretende hallar la común intención de los contratantes, como es menester en principio, en el entendido de que si dicha búsqueda resultare frustránea, igualmente creemos válido acudir a la integración del contrato, en aras de colmar el vacío reinante, pues si bien es cierto el contenido de la condición particular en esta hipótesis no podría apreciarse por ineficaz o inválido, tampoco es menos cierto que objetivamente hay un hecho incontrovertible que el hermeneuta debe considerar (el deseo de desligarse del condicionado general), y por ende, iniciar una búsqueda especial, independientemente del resultado que se obtenga. 
El segundo presupuesto, a su turno, atañe a la obvia existencia de una discrepancia, divergencia, inarmonía o contradicción entre cláusulas: una de estirpe general, y otra de naturaleza especial. Al fin y al cabo, el supuesto de hecho de la regla de la prevalencia-o de la preferencia-, es una contradicción, entendida como lo hace el Diccionario de la Real Academia Española: "1. Acción y efecto de contradecir. 2. Afirmación y negación que se oponen una a otra y recíprocamente se destruyen". Y contradecir, de acuerdo con el mismo diccionario, es: "Dicho de una persona: Decir lo contrario de lo que otra afirma, o negar lo que da por cierto".

\section{En tal virtud, la confirmación de la antinomia o el sentido contrario -o} a lo sumo divergente- de ambos textos comúnmente supone un proceso de ponderación, muy ajeno al mero ejercicio de confrontación mecánico de contenidos (automaticidad), salvo que al rompe, con el sólo parangón o cotejo, aflore indubitada la contradicción, lo que de ordinario no sucede así, según lo anticipamos, entre otras razones para evitar conclusiones que pudieren lucir precipitadas -o aparentes- en una materia tan delicada como es la interpretación, corroborándose, una vez más, que este laborío es esencialmente hermenéutico, como lo hemos ya apuntado, con todo lo

Sobre el mismo particular, el profesor Jesús AlFARo, refiriéndose al significado de este primer presupuesto, in extenso opina que es necesario que “...ambas cláusulas en conflicto sean eficaces, pues, como es natural, si una de ellas no es eficaz, el conflicto desaparece....Si la ineficacia afecta a la condición general carece de sentido, lógicamente, traer a colación la regla de la prevalencia. En cambio, si la ineficacia atañe a la condición particular, la respuesta puede ser distinta. En este caso es preciso considerar separadamente las dos consecuencias que produce la aplicación de la regla de la prevalencia, que son, por un lado, la inaplicación de la condición general discrepante y, por otro, la aplicación del acuerdo individual. Teniendo en cuenta este doble plano de consecuencias puede afirmarse a nuestro juicio que la segunda consecuencia, esto es, la aplicación del acuerdo individual sólo se produce si nos encontramos ante un acuerdo individual ineficaz, pero esto no significa que ante un acuerdo individual ineficaz haya de aplicarse, necesariamente, la condición general. La alternativa es, como puede suponerse, la aplicación del Derecho dispositivo".

"En efecto, si las partes no acuerdan nada de modo particular, debe suponerse la aplicación de las condiciones generales. Sin embargo, cuando las partes acuerdan algo separándose de lo establecido en las condiciones generales, aunque dicho acuerdo resulte ineficaz, puede tener trascendencia a los efectos de manifestar la voluntad de las partes de 'no querer' la regulación prevista en las condiciones generales, de modo que ante la ineficacia de la regulación particular estaríamos ante una laguna contractual que ha de ser cubierta de acuerdo con las reglas generales de la integración". Las condiciones generales de contratación, op. cit., p. 301.

En el Derecho de seguros, a su turno, naturalmente se demanda análoga exigencia, ya que como cabalmente lo refrenda el profesor y colega Abel VeIGA Copo,“....ambas cláusulas han de ser plenamente eficaces y válidas pues de lo contrario tal regla interpretativa sería inaplicable....El intérprete ha de preferir, en principio, el texto particular al texto general. Evidentemente si lo que ha de prevalecer es el acuerdo individual como el mejor exponente y adalid de lo que es la genuina voluntad de las partes, tal aplicación sólo es viable si nos hallamos ante un acuerdo individual eficaz". La interpretación de las condiciones en el contrato de seguro, op. cit, p. 60. 
que ello supone, con mayor razón cuando es menester llevar a cabo una lectura integral del plexo contractual (interpretación sistemática), muy distinto al simple examen aislado o insular, tal y como entre nosotros lo ordena el artículo 1622 de la codificación civil, a cuyo tenor: "Las cláusulas de un contrato se interpretarán unas por otras, dándosele a cada una el sentido que mejor convenga al contrato en su totalidad”.

Al fin de cuentas, en aplicación de la señalada regla de singular relevancia, la interpretación debe ser contextual: in globo, y no circunscribirse a un sólo segmento o fracción, por importante que sea, dado que es probable que el excursus integral, en efecto, conduzca a un resultado enteramente distinto, confirmándose la conveniencia, mejor aún la necesidad de articular, in casu, las apellidas reglas interpretativas tradiciones con las modernas. Unas y otras, lo hemos recalcado antes, están al servicio incondicional del intérprete, por manera que deben converger, en guarda de realizar un ejercicio equilibrado, a la par que responsable, y de actuar ex abundante cautela, como corresponde ${ }^{45}$.

En este mismo sentido, el profesor Angel CARrasco Perera no yerra al afirmar que, “...por medios interpretativos se constata la existencia de una contradicción”, razón por la cual, en oportunidades, la “...condición o cláusula particular podrá y deberá ser interpretada a la luz de los actos de las partes, del uso, del contexto del contrato"46.

Además de lo expresado, aun cuando íntimamente vinculado con ello, no es necesario que la referida contradicción o divergencia aflore en forma paladina, brusca o al rompe, ni tampoco en forma llana o recta via, puesto que esta no es una exigencia legal, ni tampoco jurisprudencial. Basta con que exista una inarmonía objetiva, una incompatibilidad intrínseca o un cambio susceptible de ser valorado por el intérprete, pues como bien lo expresa el Dr. Darío A. Sandoval Shaik, “...no es imprescindible que exista una contradicción directa y abierta, sino que es suficiente con que la condición general lleve a una modificación de los derechos y obligaciones establecidos en el acuerdo individual"47.

45 Vid., Vito Rizzo, Condizioni generali del contratto e predisposizione normativa, Edizioni Scientifiche Italiane, Napoli, 1983, p. 176 ss.

46 Angel Carrasco Perera. Derecho de contratos, op. cit., p. 69.

47 Darío A. Sandoval Shaik. Las condiciones generales del contrato de seguro y su control interno e internacional, op. cit., p. 242. 
Es lo que igualmente sucede en el contrato de seguro, entre otros ejemplos más, en el que con alguna frecuencia aflora una divergencia o incompatibilidad entre textos considerados generales, y texto considerados particulares (amparos y exclusiones, respectivamente), como ya anotamos, siendo suficiente que ellas se asomen y que así lo constate el intérprete, sin exigirse que sean absolutas o rotundas, bastando que sean claras, eso sí, puesto que como lo recrea el profesor I. HALPERIN, “....aun cuando no exista incompatibilidad absoluta, si del conjunto del contrato y de las circunstancias resulta que las partes han tenido la intención de derogar las condiciones generales"48.

\subsection{Limitaciones. El carácter beneficioso de las condiciones generales y su determinación}

Tal y como tuvimos oportunidad de señalar, de conformidad con puntuales opiniones doctrinales, en asocio con el contenido de algunos textos -no todos- de modernas legislaciones que se ocupan de la materia en examen, la regla de la prevalencia no siempre puede aplicarse sin realizar un juicio de valor encaminado a confirmar, no obstante la presencia de condiciones particulares que excepcionan o modifican las particulares, si el texto de las generales deviene más favorables o beneficiosas.

Dicho de otra manera, que si bien es cierto en principio cuando hay contradicción entre una condición general y una particular la discrepancia debe ser resuelta haciendo prevalecer el contenido plasmado en la condición o cláusula particular, hay que realizar una tarea adicional antes de concluir el ejercicio hermenéutico: verificar si la general, más allá de la existencia fáctica y jurídica de la particular, es más beneficiosa que ésta para el adherente, o consumidor.

Así lo dispone, formalmente, el artículo 6, numeral primero de la Ley española de 'Condiciones Generales de la Contratación', se itera, excepción que ha suscitado una acerada polémica, a la que en lo pertinente se han sumado otros académicos de otras latitudes, justamente por la tensión que se genera entre los que abogamos por la aplicación racional y equilibrada de la autonomía privada, y aquellos que se cimientan en el principio pro consumatore -en toda su intensidad, extensión y alcance

48 Issac Halperin. Seguros, op. cit, p. 357. 
ilimitado-, v.gr: en Colombia, con base en el artículo 34 de la Ley 1480 de 2011 ('interpretación favorable').

Dependiendo del resultado al que se arribe, podría entonces corroborarse o desmentirse el parecer de algunos, conforme al cual la prevalencia de las condiciones particulares, en función del referido juicio de favorabilidad, conoce excepciones, como lo estimamos igualmente nosotros, pues de lo contrario se eclipsarían los más elementales y caros postulados rectores de la ciencia del Derecho y en particular del Derecho de contratos, aún desde una perspectiva moderna -que no anárquica-, motivo por el cual pensamos que este juicio debería hacerse en un contexto diferente (in globo) y, sobre todo, con unos alcances menos extendidos, generalizados y radicales, pues de lo contrario se arrasaría la genuina esencia y el sustrato del contrato, que antes que erosionado, vive su esplendor, obviamente con necesarias cautelas.

De allí la importancia de que se consideren y examinen dos reglas que están conectadas entre sí, y que revisten en el Derecho moderno de los contratos especial valor: la regla de la condición más beneficiosa -0 favorable-, y la regla de la condición más importante -o relevante-49.

Empero, por motivos de orden y por tanto de índole metodológica que conviene observar, al que se agrega uno adicional: de espacio, cumple pasarle revista brevemente a un supuesto para nada infrecuente, que reviste no sólo trascendencia, sino que acusa alguna dificultad y que, a su manera, se entrelaza igualmente con la temática de la 'condición más beneficiosa' y con la de la 'condición más importante', por manera que vale la pena auscultarlo, a continuación, remitiendo el lector al estudio anteriormente señalado.

\section{OTROS SUPUESTOS: CONTRADICCIÓN ENTRE CONDICIONES GENERALES, ÚNICAMENTE}

Muy diferente a las hipótesis precedentes, aun cuando en cierto modo intercomunicada con ellas -lo que no es inviable-, es el caso de la con-

49 Véase, con relativo detalle, nuestro escrito: Principios rectores y reglas de interpretación de los contratos, en el que abordamos ambas reglas, de particular conexión con la temática sub examine, se itera, las que omitimos abordar en esta publicación, en obsequio a la concreción (op. cit, p.p. 565-592). 
tradicción entre condiciones de un mismo linaje o estirpe: las generales, de tal manera que la inarmonía -o discrepancia intrínseca- no se refiere a condiciones de diversa tipología: generales y particulares, stricto sensu, sino a la primera categoría de ellas, solamente.

Por lo tanto, como en el fondo el problema interpretativo suele definirse en función de la 'elección' que termine efectuando el intérprete, es menester indagar en el evento planteado cuál sería la solución que consulte cabalmente los intereses en conflicto, a sabiendas de que una de las notas que califican las condiciones generales, por definición, reside en la ausencia de configuración por parte del adherente, o consumidor, según las circunstancias, hasta el punto de que la redacción de las mismas es unilateral, en concreto a cargo del predisponente -o de un tercero, en puntuales supuestos-.

No ocuparse de este tema, así lo pensamos, dejaría pues de lado uno de los problemas hoy más complejos de la interpretación de las condiciones generales de contratación, en razón de que como lo ha constatado el profesor uruguayo Juan BENítez CAORCI, "La regulación de la temática abordada quedaría renga si no se diera solución a la discordancia fáctica que surge al encontrarnos con divergencias dentro del contenido prerredactado del contrato" 50 .

Varias respuestas, por lo tanto, se han estructurado en el Derecho comparado, aun cuando las más salientes realmente han sido dos, en general, sin perjuicio de lo acontecido, más específicamente, en sede del contrato de seguro, según se relatará en forma somera.

La primera, sintonizada con la mecánica y con lógica de la dupla: condiciones generales, y particulares, consistente en tratar de indagar de cara a las condiciones en conflicto cuál de ellas, figuradamente, es más particular, así sea por aproximación, o por aplicación, mutatis mutandis, de la regla de la especialidad: lo especial prevalece sobre lo general, a emulación de la socorrida lex specialis, postura que, por loable que pueda ser, no ha contado con el aplauso de la doctrina y de la jurisprudencia, fundamentalmente por estimarla algo artificial y por apoyarse, es cierto, en una ficción: creer-o pretender-que una condición general, en medio

50 Juan Benítez CAORCi. La interpretación en los contratos con cláusulas predispuestas, Temis, Bogotá, 2002, p. 94. 
de todo, puede llegar a ser lo que no es, ni fue, vale decir una condición particular.

O es general, ex definitione, o no lo es. Así de simple, así de claro, por lo menos para quienes pensamos que darle plena cabida a una tercera categoría de cláusulas o condiciones: las llamadas 'especiales', no es de recibo, así se resguarden bajo el alero de las apellidadas condiciones generales, a modo de subespecie o modalidad -y aún de las particulares, stricto sensu-, en un todo de acuerdo con lo ya expresado antes en este escrito, muy especialmente en el seguro, en el que se suele aludir con mayor frecuencia a ellas, aun cuando con reservas, claro está, de tal suerte que si en gracia de discusión se concluyera que las 'especiales' son generales, pero más específicas, estas estarían entonces llamadas a primar, de plano, sobre las 'más' generales, valga tanta repetición, solución que no se nos antoja satisfactoria, se reitera, como quiera que, por absoluta, y también por desconocer el proceso de gestación unilateral de tales condiciones (etiología funcional), no estimamos que pueda revelar, per se, la auténtica intentio de los contratantes, menos del asegurado, por regla.

La segunda, con mejor fortuna, más allá de puntuales discrepancias dogmáticas referentes a su modus operandi y a sus basamentos, ha aspirado a ser más realista y aterrizada, para lo cual se han trazado primordialmente dos caminos.

El primero de ellos, validando las circunstancias del caso, de haberlas, y atendidas la naturaleza y la finalidad del negocio jurídico celebrado, entre otros eslabones (elementos esenciales, economía del contrato, etc.), pretende solucionar la discrepancia en comento, en virtud de la que se ha denominado regla de la condición más importante -o relevante-.

En segundo de ellos, sin desconocer la entidad de la referida tesitura, opta por darle cabida a la regla de la favorabilidad respecto al adherente, o sea a la regla de la condición más beneficiosa.

En su orden, y por su inescindible relación con el tema que detiene nuestra atención, y por el hecho de que en varias temáticas atinentes a la moderna interpretación de los contratos ellas son consideradas y examinadas por la doctrina y la jurisprudencia, a renglón seguido mencionaremos y pincelaremos ambas reglas, así: 
Primeramente a la regla de la condición más importante, y a continuación de la regla de la condición más beneficiosa, no sin antes anticipar nuestra inclinación, en términos generales, por el primero de los descritos caminos (regla de la condición más importante o relevante), sin perjuicio de que, si la búsqueda de lo realmente pretendido por las partes no puede hacerse con arreglo a las pautas hermenéuticas allí trazadas, a nuestro juicio más a tono con la esencia del acto hermenéutico y con su desenvolvimiento, el intérprete pueda $-\mathrm{y}$ deba- entonces acudir a la regla de la condición más beneficiosa, en los términos plasmados por la dogmática y en los que, en lo aplicable, establece entre nosotros el art. 34 del nuevo Estatuto del consumidor (Ley 1480/2011).

Lo anterior, obviamente en los casos en que resulte aplicable la citada Ley 1480 , fundamentalmente por cuanto ella no rige todas y cada una de las relaciones jurídicas inscritas en sede de la contratación moderna, ni tampoco la integridad de contratos masivos y los celebrados con arreglo a condiciones generales, luego dicha precisión vale la pena tenerla presente, pues es probable que se piense que el radio de acción del nuevo estatuto sea tan amplio que, sin distingo, las abarque a todas y cada una de ellas, como si los Códigos Civil y de Comercio, en asocio de otras fuentes normativas especiales, en efecto, no fuera menester observar, so capa de hacer parte del ancien régime, o del jus vetum (vetera).

Nada, es cierto, más alejado de la realidad jurídica, y del concierto hermenéutico, concebido rectamente como un 'sistema', o también como un tejido integrado por hilos y por capas, insumos del telar interpretativo en el que el hermeneuta, a posteriori, fija el contenido del contrato otrora celebrado (acto de fijación), dándole luego, correlativamente, la inteligencia que mejor se avenga con el mismo (acto de entendimiento y de ulterior revelación).

\section{BIBLIOGRAFÍA}

Alfaro Aguila-Real, Jesús. Las condiciones generales de la contratación, Civitas, Madrid, 1993, p. 299.

Alvarez González, Santiago. Condiciones generales en la contratación internacional, La Ley, Madrid, 1992. 
Ballesteros Garrido, José Antonio. Las condiciones generales de los contratos y el principio de la autonomía de la voluntad, Bosch, Barcelona, 1999.

Benítez Caorci, Juan. La interpretación en los contratos con cláusulas predispuestas, Temis, Bogotá, 2002.

Caballero Sánchez, Ernesto. El consumidor de seguros: protección y defensa, Fundación Mapfre Estudios, Madrid, 1997.

Carrasco Perera, Angel. Derecho de contratos, Aranzadi-Thomson Reuters, Pamplona, 2010.

Castello Matrán, Julio y Guardiola, Antonio. Diccionario Maprfre de seguros, Fundación Mapfre, Madrid, 2008.

Coca Payeras, M. "Comentario al art. 10.1.b), LGDCU”, en Comentarios a la Ley General de Defensa de los Consumidores y Usuarios, Madrid, 1992.

Contreras Strauch, Osvaldo. Derecho de seguros, Legal Publising y Thomson Reuters, Santiago, 2014.

Corte Suprema de Justicia, Sentencia del 4 de noviembre de 2009.

Corte Suprema de Justicia, Sentencia del 24 de julio de 2012.

De Nova, Giorgio. "Le condizioni generali di contratto", en Trattato di diritto privato. Obbligazioni e contratti, UTET, Torino, 1982

Del Caño Escudero, Fernando "El contenido mínimo de la póliza en la Ley de Contrato de Seguro", en Comentarios a la Ley de Contrato de Seguro, T. I, Colegio Universitario de Estudios Financieros, Madrid, 1982.

Di Majo, Adolfo. "Il contenuto del contratto", en La disciplina generale dei contratti, Giapichelli Editore, Torino, 1999.

Díaz Alabart, Silvia y Alvarez Moreno, María Teresa. Manual de derecho del consumo, Reus, Madrid, 2016.

Donati, Antigono. Trattato del diritto delle asicurazioni private, T.II, Giuffrè, Milano, 1954.

Estigarriba Biber, María Laura. "Evolución de los principios de interpretación de los contratos, con especial referencia a la República Argentina”, en Tratado de la interpretación del contrato en América Latina, T.I, Grijley, Lima, 2007.

Ferrer Riba, Josep. "Reglas de interpretación”, en Comentarios a la ley de condiciones generales, Civitas, Madrid, 2002, p. 362. 
Favree Rochex, André y Courtieu, Guy. Le droit du contrat d'assurance terrestre, L.G.D.J, Paris, 1998.

Fontaine, Marcel. Droit des assurances, Larcier, Bruxelles, 1996.

García Amigo, Manuel. Las condiciones generales de los contratos, Editorial Revista de Derecho Privado, Madrid, 1969.

Garrigues, Joaquín. Contrato de seguro terrestre, Imprenta Aguirre, Madrid, 1980.

González de Alaiza Cardona, José Javier y Pertínez Vílchez, Francisco. "Los contratos de adhesión y la contratación electrónica”, en Tratado de contratos, T. II, Tirant lo blanch, Valencia, 2011.

Halperin, Issac. Seguros. Exposición crítica de las Leyes 17.418 y 20.091, en coautoría con el Profesor Juan Carlos Félix Morandi, Buenos Aires, 1983.

Jaramillo J., Carlos Ignacio, La configuración del siniestro en el seguro de la responsabilidad civil, Universidad Javeriana y Editorial Temis, Bogotá, 2011.

--- Principios rectores y reglas de interpretación de los contratos, Universidad Javeriana, Universidad de Perugia y Grupo Editorial Ibañez, Bogotá, 2016.

--- La doctrina de los actos propios. Valor y significado de la regla latina venire contra factum proprium en el ámbito contractual, op. cit.

--- La Corte Suprema de Justicia, en sentencia del 2 de febrero de 2001, (M.P. Carlos Ignacio Jaramillo J., Sala de Casación Civil).

--- Estructura de la forma en el contrato de seguro, Temis, Bogotá, 1986.

--- Interpretación, calificación e integración del contrato, Universidad Javeriana y Grupo Editorial Ibañez, Bogotá, 2014.

Kullmann, Jérome. Lamy assurances, Kluwer, Paris, 2005.

Lambert Faivre, Yvone. Droit des assurances, Dalloz, Paris, 2005.

Lima Marques, Claudia. "Notas sobre a intererpretaçao dos contratos no directo privado brasileiro: As linhas gerais sobre interpretação do Código Civil de 2002 e do Código de Defensa do consumidor de 1990", en Tratado de la interpretación del contrato en América Latina, T.I, Grijley, Lima, 2007.

López de Zavalía, Fernando J.. Teoría de los contratos. Parte general., Víctor P. de Zavalía, Buenos Aires, 1984. 
López Santa María, Jorge. Los contratos, Parte general, Editorial Jurídica de Chile, 1986.

Maleville, Marie-Hélene. L'interprétation des contrats d'assurance terrestre, L.G.D.J, Paris, 1996.

Messineo, Francesco. Doctrina general del contrato, T.I, E.J.E.A, Buenos Aires, 1952 .

Morandi, Juan Carlos Félix. Estudios de derecho de seguros, Ediciones Pannedille, Buenos Aires, 1971.

Ordóñez Ordóñez, Andrés. "Las nuevas tendencias del derecho de seguros en las legislaciones más recientes de los países latinoamericanos", en Revista Iberolatinoamericana de seguros, No 40, Universidad Javeriana, AIDA-CILA, Bogotá, 2014.

Ossa G., Efrén J. Teoría general del seguro. El contrato, Temis, Bogotá, 1991.

Pagador L., Javier. Condiciones generales y cláusulas contractuales predispuestas, Marcial Pons, Madrid, 1999.

Pérez-Serrabona G, José Luis La póliza y la documentación del contrato de seguro, Editorial Comares, Granada, 2003.

Pertíñez Vílchez, Francisco. "Los contratos de adhesión y la contratación electrónica”, en Tratado de contratos, T. II, Tirant lo blanch, Valencia, 2011.

Picard, M. y Besson, A. Les assurances terrestres. Le contrat d'assurance, T, I, L.G.D.J, Paris, 1982.

Rizzo, Vito. Condizioni generali del contratto e predisposizione normativa, Edizioni Scientifiche Italiane, Napoli, 1983.

Roca Guillamón, Juan “Reglas de interpretación de las condiciones generales de los contratos", en Condiciones generales de la contratación y cláusulas abusivas, Lex Nova y Consejo General de los Colegios Oficiales de Corredores de Comercio, Valladolid, 2000.

Rosetti, Marco. Il diritto delle assicurazioni. Il contratto di assicurazione in generale, T.I, CEDAM, Padova, 2011.

Salandra, Vittorio. Dell' Assicurazione. Libro quarto. Delle obbligazioni, Zanichelli Editore, Bologna, 1966.

--- "I contratti di adesione”, en Rivista di Diritto. Commerciale, 1928. 
Sandoval Shaik, Darío A. Las condiciones generales del contrato de seguro y su control interno e internacional, Universidad Complutense de Madrid, 2014.

Sánchez Calero, Fernando. Ley de contrato de seguro, Aranzadi, Pamplona, 1999, p. 182.

Scalfi, Gianguido. I contratti di assicurazione. L'assicurazione danni, UTET, Torino, 1991.

Soto Coaguila, Carlos. "Las reglas de interpretación de los contratos en el derecho peruano", en Tratado de la interpretación del contrato en América Latina, Grijley, 2007.

Stiglitz, Rubén y Gabriel. Contratos por adhesión, Depalma, Buenos Aires, 2015

Stiglitz, Rubén . "Nuevos temas incorporados en la teoría general del contrato en el Código Civil y Comercial de la Nación”, en Contratos en el nuevo Código Civil y Comercial, Thomson Reuters, La Ley, Buenos Aires, 2015.

--- Derecho de seguros, T. I, Abeledo Perrot, Buenos Aires, 1998.

--- Contratos civiles y comerciales, T. I, Abeledo-Perrot, Buenos Aires, 1998.

Veiga Copo, Abel. "La interpretación de las condiciones en el contrato de seguro", en Revista de responsabilidad civil y seguro, año, p. 66.

--- Caracteres y elementos del contrato de seguro. Póliza y clausulado. Universidad Sergio Arboleda. Biblioteca Jurídica Diké. Bogotá. 2010.

Verdera Izquierdo, Beatriz. "La interpretación de los contratos a partir de los Principios Contractuales Europeos", en Bases de un derecho contractual europeo, Tirant lo blanch, Valencia, 2003.

Villa Zapata, Walter. "Reglas de interpretación del contrato de seguro", en Derecho de seguros, Homenaje de la Asociación Argentina de Derecho de Seguros -Rama de la A.I.D.A- al profesor Juan Carlos Félix Morandi, Hammurabi, Buenos Aires, 2001. 
